NBER WORKING PAPER SERIES

\title{
A NEW LOOK AT RACIAL PROFILING: EVIDENCE FROM THE BOSTON POLICE DEPARTMENT
}

\author{
Kate L. Antonovics \\ Brian G. Knight \\ Working Paper 10634 \\ http://www.nber.org/papers/w10634
}

\author{
NATIONAL BUREAU OF ECONOMIC RESEARCH \\ 1050 Massachusetts Avenue \\ Cambridge, MA 02138 \\ July 2004
}

We thank Peter Arcidiacono, Eli Berman, Richard Carson, Kim Sau Chung, Hanming Fang, Roger Gordon, Nora Gordon and Winfried Koeniger for their comments. We would also like to thank seminar participants at the St. Louis Federal Reserve, UC-Irvine, UCLA and USC, and participants at the IZA Workshop on The Nature of Discrimination. We have also benefitted from discussions with Amy Farrall at Northeastern University and Carl Walter at the Boston Police Department. Finally, we are indebted to Bill Dedman at The Boston Globe for providing us with our data. The views expressed herein are those of the author(s) and not necessarily those of the National Bureau of Economic Research.

(C2004 by Kate L. Antonovics and Brian G. Knight. All rights reserved. Short sections of text, not to exceed two paragraphs, may be quoted without explicit permission provided that full credit, including $\mathbb{C}$ notice, is given to the source. 
A New Look at Racial Profiling: Evidence from the Boston Police Department

Kate L. Antonovics and Brian G. Knight

NBER Working Paper No. 10634

July 2004

JEL No. K0, H0

\section{$\underline{\text { ABSTRACT }}$}

This paper provides new evidence on the role of preference-based versus statistical discrimination in racial profiling using a unique data set that includes the race of both the driver and the officer. We first generalize the model presented in Knowles, Persico and Todd (2001) and show that the fundamental insight that allows them to distinguish between statistical discrimination and preference-based discrimination depends on the specialized shapes of the best response functions in their model. Thus, the test that they employ is not robust to a range of alternative modeling assumptions. However, we also show that if statistical discrimination alone explains differences in the rate at which the vehicles of drivers of different races are searched, then search decisions should be independent of officer race. We then test this prediction using data from the Boston Police Department. Consistent with preference-based discrimination, our baseline results demonstrate that officers are more likely to conduct a search if the race of the officer differs from the race of the driver. We then investigate and rule out two alternative explanations for our findings: race-based informational asymmetries between officers and the assignment of officers to neighborhoods.

Kate L. Antonovics Department of Economcis University of California, San Diego kantonov@ucsd.edu

Brian G. Knight Brown University Department of Economics, Box B 64 Waterman Street Providence, RI 02912 and NBER brian_knight@brown.edu 


\section{A New Look at Racial Profiling: Evidence from the Boston Police Department}

To date, there have been over 200 court cases involving allegations of racial and ethnic profiling against law enforcement agencies in the United States. Typically, the focus in these cases has been on uncovering why law enforcement officials treat individuals from different racial groups differently. On the one hand, the courts have tended to uphold racially biased policing patterns when they can be reasonably justified by racial differences in crime rates. On the other hand, the courts have consistently ruled against what appear to be purely racist policing practices. The problem, of course, is that it is not easy to empirically distinguish between these two possibilities.

Economists, who have long struggled with explaining racial disparities in labor market outcomes, have now joined the debate over racial profiling, and a number of recent papers have attempted to determine whether the observed racial disparities in policing patterns are best explained by models of statistical discrimination or models of preference-based discrimination (see, for example, Knowles, Persico and Todd (2001), Hernández-Murillo and Knowles (2003), Anwar and Fang (2004) and Dharmapala and Ross (2004)).

In models of statistical discrimination, discrimination arises because law enforcement officials are uncertain about whether a suspect has committed a particular crime. Thus, if there are racial differences in the propensity to commit that crime, then the police may rationally treat individuals from different racial groups differently. On the other hand, in models of preference-based discrimination, discrimination arises because the police have discriminatory preferences against members of a particular group and act as if there is some non-monetary benefit associated with arresting or detaining members of that group. Thus, preference-based discrimination refers to anything that raises the benefit (or, equivalently, lowers the cost) of searching motorists from one group relative to those from some other group. ${ }^{1}$

This debate among economists over the sources of racial disparities in policing patterns roughly parallels the debate over racial profiling within the court system. That is, statistical discrimination approximately corresponds to the type of behavior that the courts have tended to uphold, while preference-based discrimination approximately corresponds to the type of behavior that the courts have tended to condemn. For this reason, economic theory and economic analysis may lead to insights that are useful in litigating these hotly-contested court cases.

\footnotetext{
${ }^{1}$ For a complete discussion of models of statistical discrimination and preference-based discrimination see Arrow (1973) and Becker (1954), repsectively.
} 
In this paper, we attempt to understand the reasons for observed racial differences in the rate at which the vehicles of African-American, Hispanic and white motorists are searched during traffic stops. In doing so, we contribute to the literature on racial profiling in a number of ways. First, we clarify the model of police search developed in Knowles, Persico and Todd (2001) (hereafter, often, KPT) and show that the fundamental insight that allows them to distinguish between statistical discrimination and preference-based discrimination is not robust to a range of alternative modelling assumptions.

According to their model, in the absence of preference-based discrimination, the probability of guilt conditional on search will be the same for all identifiable groups of motorists. The logic is that, since the police will always search motorists for whom the likelihood of finding drugs exceeds the cost of search, in equilibrium, the drug trafficking behavior of motorists must adjust to equate the probability of guilt conditional on search for all individuals. The power of this insight is that, even if black and white motorists differ along dimensions other than race, the probability of guilt conditional on search will still be the same for all groups. This is critical since it is generally impossible to distinguish between statistical discrimination on the basis of race and statistical discrimination on the basis of characteristics that are correlated with race but that are unobserved to the econometrician (see for example, Altonji and Pierret (2001) and Dharmapala and Ross (2004)).

On the other hand, according to the model in KPT, if officers have discriminatory preferences, then the probability of guilt conditional on search will differ across racial groups. KPT then examine traffic stop data from the State of Maryland. They find that the probability of guilt conditional on search does not differ (in a statistical sense) across racial groups and interpret this as evidence that officers do not have discriminatory preferences.

As we show below, however, the logic of the test that KPT employ hinges upon the specialized shapes of the best response functions in the mixed strategy equilibrium of their model. As a result, their model's predictions are sensitive to a range of alternative modelling assumptions. For example, in this paper, we focus on the possibility that officers are heterogeneous in their preferences for search. Indeed, our data (which we discuss below) supports the notion that, all else equal, officers differ in their tendency to search motorists. In the presence of this type of heterogeneity, even in the absence of preference-based discrimination, the probability of guilt conditional on search need not be the same across all identifiable groups of motorists. Thus, if there are racial differences in the propensity to carry drugs, then guilt rates conditional on search also may differ by race.

In KPT, equilibrium differences in the probability of guilt conditional on search cannot 
persist because officers always search motorists if the likelihood of finding drugs exceeds the cost of search. However, with officer heterogeneity, officers with very high search cost are unlikely to ever search motorists. Since there is some chance that motorists will not be searched, equilibrium differences in the probability of guilt conditional on search across different racial groups can exist, even in the absence of preference-based discrimination.

Anwar and Fang (2004) and Bjerk (2004) highlight another reason why probability of guilt conditional in search may differ across groups even in the absence of preference-based discrimination. In particular, suppose the police observe some characteristic that is not perfectly known to the motorist at the time he or she makes the decision to carry drugs, but that is correlated with the likelihood that the motorist carries drugs. For example, motorists who traffic drugs may know that they are more likely to appear nervous if they carry drugs than if they do not, but they may not be able to perfectly predict how nervous they will appear. In this setting, the police will use motorists' behavior to update their prior beliefs about the likelihood that motorists from different racial groups traffic drugs. Further, racial differences in the propensity to carry drugs will lead to differences in the probability of guilt conditional on search. Bjerk (2004) and Dharmapala and Ross (2004) also point out that if the police cannot observe all potential criminals, then guilt rates conditional on search also may vary by race. ${ }^{2}$ Below, we relate these critiques to our own.

In order to circumvent these problems, we develop an alternative mechanism for testing between these two forms of discrimination. In particular, we show that if statistical discrimination alone explains differences in the rate at which African-American and white drivers are pulled over, then search decisions should be independent of the race of the police officer.

We then test this prediction using a unique data set in which we are able to match the race of the officer to the race of the driver for every traffic stop made by officers in the Boston Police Department for the two-year period starting in April 2001. ${ }^{3}$ Thus, in addition to being able to discern differences in the likelihood that motorists from different racial groups are subject to search, we are also able to determine whether these patterns differ depending on the race of the officer. Previous studies of racial profiling have lacked the officer-level data required for this type of analysis. ${ }^{4}$

We find that, even after controlling for a broad set of covariates including the location of the stop, if the race of the officer differs from the race of the driver, then the officer is more

\footnotetext{
${ }^{2}$ Dharmapala and Ross (2004) also discuss the implications of allowing heterogeneity in the severity of drug offenses.

${ }^{3}$ For an alternative discussion of these data, see the series of articles by Bill Dedman and Francie Latour (2003).

${ }^{4}$ One exception is Anwar and Fang (2004), which is discussed below.
} 
likely to conduct a search. These results cannot be explained by standard models of statistical discrimination and are consistent with preference-based discrimination. We then investigate two alternative explanations for these empirical findings. First, we examine whether these patterns could arise because of differences in the ability of African-American and white police officers to accurately assess the guilt of motorists from different racial groups. However, we find that our results hold even among officers with greater than 10 years of experience, amongst whom informational asymmetries should be less severe. Finally, we investigate (and rule out) the possibility that our findings could be explained by the way in which officers are assigned to various neighborhoods within the city.

\section{Some Initial Trends in the Data}

In order to motivate our model and the analysis that follows, it is worthwhile to first highlight a few patterns in our data. For now, these patterns are merely meant to be suggestive, and we will discuss the data in greater detail below.

Table 1 presents, by officer race and motorist race, the probability that a motorist's car is searched during a traffic stop. Looking at the last column, we see that both Hispanics and blacks are almost twice as likely as are whites to have their cars searched. This differential search pattern could be the result of preference-based discrimination. However, it is also consistent with statistical discrimination. That is, if blacks and Hispanics are more likely to carry drugs or other contraband than are whites, then it is also possible that they are also more likely than whites to raise the suspicion of the police. Thus, the last column of Table 1 simply reiterates the well-known fact that racial disparities in search rates exist, but does not offer any insight into why those disparities might arise.

Columns 2-4, however, are more revealing; motorists are, in general, more likely to be searched if the officer making the stop is from a different racial group from that of the motorist. For example, the probability that a white motorist is searched is .41 percent if the officer is white and .67 percent if the officer is black. Similarly, the probability that a black motorist is searched is .81 percent if the officer is black but 1.0 percent if the officer is white. In order to insure that the patterns in Table 1 are not driven by a small number of officers who issue an unusually large number of tickets, Table 2 weights each citation by the inverse of the number of citations given by the officer issuing the citation. Since officers who issue a large number of tickets are less likely to conduct searches than officers who issue a small number of tickets, the search probabilities are generally larger in Table 2 than in Table 1. However, as in Table 1, we see that motorists are consistently less likely to be searched if the 
officer making the stop is a member of the motorist's own racial group.

Abstracting at this stage from issues of statistical significance and other possible concerns, we merely wish to point out that the patterns in Tables 1 and 2 are inconsistent with standard models of statistical discrimination in which racial differences in the rate at which motorists are searched arise because the police believe that motorists from some racial groups are more likely to have contraband than are motorists from other groups. Since these beliefs must be correct in equilibrium, there should be no difference in the rate at which officers from different racial groups search the vehicles of motorists from a particular racial group. On the other hand, preference-based discrimination could explain these patterns. In particular, if officers favor members of their own racial group, then we would expect search rates to be lower when there is a match between the race of the officer and the race of the motorist.

However, two alternative explanations also come to mind. First, there may be racial differences in the ability of officers to accurately discern the likelihood that motorists from different racial groups are guilty. For example, it is natural to think that officers may be better able to assess the guilt of motorists who are members of their own racial group. A second explanation for the differential search rates in Tables 1 and 2 involves the mechanism through which officers are assigned to various neighborhoods within the city. For example, if white officers are assigned to neighborhoods in which crimes are more likely to be committed by blacks than whites, and if black officers are assigned to neighborhoods in which crimes are more likely to be committed by whites than blacks, then we might expect that, for the

city as a whole, white officers would be more likely than black officers to search the cars of black motorists. We address both of these alternative explanations in the final sections of the paper.

\section{The Model}

In this section, we re-examine the model of police search presented in Knowles, Persico and Todd (2001), and show that the fundamental insight that allows them to empirically distinguish between preference-based discrimination and statistical discrimination hinges on the specialized shapes of the best response functions in the game that they analyze.

Motorists are assumed to be either African-American or white, denoted by $a$ and $w$, respectively. In addition, motorists are distinguished by some characteristic, $c$, that is potentially useful to the police in determining whether or not to search a motorist's car. Importantly, however, $c$ may be not be perfectly observed by the econometrician. Of central importance is whether it is possible to distinguish between statistical discrimination and 
preference-based discrimination even when the econometrician does not observe the full range of motorist characteristics observed by the police.

In deciding whether or not to carry drugs, motorists weigh the benefit of carrying drugs against the penalty of being caught. If a driver does not carry drugs, then his payoff is assumed to be zero regardless of whether or not his car is searched. However, if a motorist from racial group $r$ carries drugs, then he faces cost $-j(c, r)$ if his car is searched and benefit $\nu(c, r)$ if his car is not searched.

Let $\gamma(c, r)$ be the probability the police search motorists of type $(c, r)$. Thus, the expected payoff to carrying drugs for motorists of type $(c, r)$ is given by

$$
-\gamma(c, r) j(c, r)+[1-\gamma(c, r)] \nu(c, r) .
$$

Motorists are playing a best response to the search behavior of police if they carry drugs whenever the above expression is greater than zero. Thus occurs when

$$
\gamma(c, r)<\frac{\nu(c, r)}{j(c, r)+\nu(c, r)} .
$$

The police cannot perfectly observe whether a motorist of type $(c, r)$ is carrying drugs. Instead, it is assumed that police maximize the expected payoff from making an arrest minus the cost of search. The benefit to making an arrest is normalized to one so that the cost of search is relative to the benefit. Let $t_{r}$ be cost of searching a motorist from group $r$, where it is assumed that $0<t_{r}<1$ to rule trivial equilibria. ${ }^{5}$

Let $\pi(c, r)$ denote probability that a motorist of type $(c, r)$ is carrying drugs. Thus, the expected payoff to officers from searching motorists of type $(c, r)$ is given by

$$
\pi(c, r)-t_{r}
$$

Officers are playing a best response to the drug trafficking behavior of motorists if they search whenever the above expression is greater than zero. Figure 1 graphs the best response function for officers and motorists. For motorists of type $(c, r)$, the line labelled $\gamma(c, r)$ represents the best response function of police and the line labelled $\pi(c, r)$ represents the best response function of motorists.

As the figure reveals, the best response functions in this game are equivalent to those in a standard matching pennies game. Thus, for motorists of type $(c, r)$, there is a unique mixed strategy equilibrium of this game in which the search behavior of the police renders motorists indifferent between carrying drugs and not carrying drugs, and the drug trafficking behavior

\footnotetext{
${ }^{5}$ The model implicitly assumes that if the police search a motorist who has drugs, then the police will find the drugs. We discuss the more general case of imperfect search below.
} 
of motorists renders the police indifferent between searching and not searching. That is, in equilibrium the probability that the police search motorists of type $c, r$ is given by

$$
\gamma^{*}(c, r)=\frac{\nu(c, r)}{j(c, r)+\nu(c, r)} .
$$

and the probability that motorists carry drugs is given by

$$
\pi^{*}(c, r)=t_{r}
$$

Since the police randomly select motorists from this group, the probability of guilt conditional on search is exactly equal to $\pi^{*}(c, r)$, the probability that motorists carry drugs.

Before analyzing how statistical discrimination and preference-based discrimination manifest themselves in this model, it is worth enriching the model to allow for heterogeneity in motorists' utility from trafficking drugs. ${ }^{6}$ In particular, we assume that the benefit to carrying drugs is given by

$$
-\gamma(c, r) j(c, r)+[1-\gamma(c, r)] \nu(c, r)-Z,
$$

where $Z$ represents an idiosyncratic cost of carrying drugs. Thus, letting $G(\cdot)$ denote the distribution of $Z$ in the population, the probability that motorists of type $(c, r)$ traffic drugs is given by

$$
G(-\gamma(c, r) j(c, r)+[1-\gamma(c, r)] \nu(c, r))
$$

Figure 2 plots the corresponding best response functions for motorists and officers.

As in Knowles, Persico and Todd, we now examine the implications of statistical discrimination and preference-based discrimination for the equilibrium of this model. Police officers in this model are defined to have discriminatory tastes if the cost of search varies by the race of the motorist, so that $t_{a} \neq t_{w}$. For example, Figure 3 displays the best response functions when officers discriminate against African-Americans so that $t_{a}<t_{w}$. As Figure 3 reveals, if $t_{a}<t_{w}$, then, among motorists with characteristic $c$, the police will be more likely to search African-Americans than whites $\left(\gamma^{*}(c, a)>\gamma^{*}(c, w)\right)$, and African-Americans will be less likely than whites to traffic drugs $\left(\pi^{*}(c, a)<\pi^{*}(c, w)\right)$.

In this model, police statistically discriminate on the basis of race if, among motorists with the same characteristic, $c$, the probability of search differs by the race of the motorist because of racial disparities in the propensity to carry drugs. This occurs whenever the net benefit of carrying drugs differs by race. That is, if $-j(c, r)$ and $\nu(c, r)$ vary by $r$, then so will the equilibrium probability of search. Figure 4 shows an example in which, even among

\footnotetext{
${ }^{6}$ Knowles, Persico and Todd also discuss this extension on page 214 of their paper.
} 
motorists with the same observable characteristic, $c$, the net benefit of carrying drugs is higher for African Americans than it is for whites, but the cost of search is assumed to be the same for all motorists, so that $t_{a}=t_{w}=t$. In this case, for any given search probability $\gamma$, African-American are more likely than whites to carry drugs, and, as the figure reveals, in equilibrium, the police are more likely to search African-American motorists than white motorists $\left(\gamma^{*}(c, a)>\gamma^{*}(c, w)\right)$. Importantly, however, the probability of guilt conditional on search is independent of the motorists race $\left(\pi^{*}(c, a)=\pi^{*}(c, w)=t\right)$.

Thus, in KPT, statistical discrimination has no effect on the probability of guilt conditional on search whereas preference-based discrimination does. In fact, as long as $t_{a}=t_{w}=t$, the probability of guilt conditional on search will be the same for all motorists regardless of their race and regardless of their observable characteristic, $c$. This is important since it implies that the econometrician need not observe $c$ to distinguish between statistical discrimination and preference-based discrimination. That is, according to the logic of KPT, it is only necessary to observe the probability of guilt conditional on search by race. Guilt probabilities that differ by officer race provide evidence in favor of preference-based discrimination. Otherwise, differential search rates solely reflect statistical discrimination.

However, Figure 4 also makes clear the fact that the test that KPT adopt depends on the specialized step-shaped best response function for police officers. Thus, any alteration to the model that smoothes out the best response function for police officers will render their test invalid. One such alteration is to allow the police to be heterogenous in their preferences for search. Indeed, this type of heterogeneity is often used to justify the randomization that characterizes most mixed-strategy equilibria (for example, see Harsanyi (1973)). In addition, our data from Boston suggest that officers do vary in their preferences for search in the sense that we observe substantial variation across officers in the likelihood that they search motorists whom they have pulled over.

Formally, we assume that the cost of searching motorists from group $r$ is given by $t_{r}+U$, where $U$ captures a mean-zero, idiosyncratic search cost. With this cost, an officer is playing a best response to motorists of type $(c, r)$ if they search whenever

$$
\pi(c, r)-t_{r}-U>0 .
$$

Letting $H(\cdot)$ denote the distribution of $U$ among officers, the probability that optimizing officers search is given by

$$
H\left(\pi(c, r)-t_{r}\right)
$$

which is clearly increasing in $\pi(c, r)$. Figure 5 plots best response functions with heterogeneity in both motorist preferences for trafficking drugs and officer search costs. In this figure, we 
plot the best response function for both African-American and white motorists of type $c$ under the assumption that the net benefit to trafficking drugs is higher for African-Americans than it is whites and under the assumption that $t_{a}=t_{w}=t$.

As shown, statistical discrimination, like preference-based discrimination, now affects $\pi^{*}(c, r)$, the probability of guilt conditional on search. Thus, in this generalized model, the test that KPT employ no longer distinguishes between preference-based discrimination and statistical discrimination.

In addition, even if there are no racial differences in the propensity to traffic drugs among motorists with identical characteristics, problems will arise if the econometrician does not observe the same set of characteristics as do the police and if those unobserved characteristics are correlated with the race of motorists and the likelihood that motorists traffic drugs. For example, suppose that the police are more likely to find drugs in cars with tinted windows than in those without. Then, if tinted windows are correlated with race and if the econometrician cannot observe whether a motorist's windows are tinted, there will be measured racial differences in the probability of guilt conditional on search.

Another alteration to the model presented in KPT that leads to smooth, upward-sloping best response functions for police officers is to assume, like Anwar and Fang (2004) and Bjerk (2004), that officers can observe some characteristic, $\theta$, that is correlated with the likelihood that the motorist is guilty, but that (unlike $c$ ) is unknown to the motorist at the time that he or she decides to traffic drugs. In can be shown that, in this setting, the best response function for officers will have the same upward-sloping shape as the best response function for officers in Figure $5 .^{7}$ In addition, if officers are not able to perfectly observe some groups of criminals (as suggested by Bjerk (2004) and Dharmapala and Ross (2004)), then this will also affect the step-shaped best response function of police officers.

\section{An Alternative Test}

In this section we propose a simple alternative test to distinguish between preference-based discrimination and statistical discrimination. We start from the supposition that if officers have discriminatory preferences, then those prejudices will be directed towards motorists who are not members of that officer's racial group. That is, the cost of search, $t$, will depend on the match between the race of the officer and the race of the motorist. We assume that, like motorists, officers belong to one of two racial groups: African-Americans and whites. Let $t_{r}^{j}$

\footnotetext{
${ }^{7}$ The models in Anwar and Fang (2004) and Bjerk (2004) highlight the added problem that the guilt rate for the marginal motorist will not equal the guilt rate for the average motorist. A complete analysis of how these models affect the shape of the best response functions is available upon request.
} 
denote the cost to officers from group $j$ of searching motorists from group $r$.

Thus, the payoff to officers from group $j$ of searching motorists from group $r$ becomes

$$
\pi(c, r)-t_{r}^{j}-U
$$

Let $\gamma^{j}(c, r)$ denote the probability that officers from group $j$ search motorists from group $r$ and let $\rho$ denote the proportion of officers from who are African-American. Thus, the payoff to motorists from group $r$ with idiosyncratic cost $Z$ from trafficking drugs is given by

$$
-\gamma(c, r) j(c, r)+[1-\gamma(c, r)] \nu(c, r)-Z,
$$

where $\gamma(c, r)=\rho \gamma^{a}(c, r)+(1-\rho) \gamma^{w}(c, r)$.

An equilibrium for motorists of type $(c, r)$ occurs at any $\pi^{*}(c, r), \gamma^{a *}(c, r)$, and $\gamma^{w *}(c, r)$ such that

$$
\begin{gathered}
\gamma^{a *}(c, r)=H\left(\pi^{*}(c, r)-t_{r}^{a}\right) \\
\gamma^{w *}(c, r)=H\left(\pi^{*}(c, r)-t_{r}^{w}\right)
\end{gathered}
$$

and

$$
\pi^{*}(c, r)=G\left(-\gamma^{*}(c, r) j(c, r)+\left[1-\gamma^{*}(c, r)\right] \nu(c, r)\right)
$$

where $\gamma^{*}(c, r)=\rho \gamma^{a *}(c, r)+(1-\rho) \gamma^{w *}(c, r)$.

Figure 6 graphs the best response functions and the equilibrium outcome of this model for motorists of type $(c, r)$ under the assumption that $t_{r}^{w}<t_{r}^{a}$ so that white officers find it less costly to search motorists from group $r$ than do African-American officers. The notion here is that white officers have discriminatory preferences against group $r .{ }^{8}$ As one might expect, white officers will be more likely to search motorists from group $r$ than will African-American officers in equilibrium. By contrast, if $t_{r}^{a}=t_{r}^{w}=t$, then officers from both groups will be equally likely to search motorists of type $(c, r)$. Thus, one clear implication of the model is that, in the absence of preference-based discrimination, there should be no difference in the rate at which officers from different racial group search drivers of type $(c, r)$. This insight forms the basis of the empirical strategy that we employ.

\section{Empirical Strategy}

In this section, we discuss how we test our model's prediction. Recall that our model predicts that, in the absence of preference-based discrimination, there should be no difference in the rate at which officers from different racial groups search motorists of type $(c, r)$. Thus,

\footnotetext{
${ }^{8} \mathrm{Or}$, equivalently, that African-American officers exhibit favoritism towards group $r$.
} 
assuming that the officer's race, the motorist's race and $c$ are known, this implication can be tested. Below we discuss what happens if $c$ is unobserved. However, in order to establish the link between our model and our empirical strategy, it is useful to start with the case in which $c$ is observed.

In order to motivate the probit model that we employ, recall that officers of race $j$ search drivers of race $r$ and characteristics $c$ with the following probability:

$$
\operatorname{Pr}(\operatorname{search} \mid j, c, r)=H\left[\pi(c, r)-t_{r}^{j}\right] .
$$

Note that equilibrium guilty probabilities $[\pi(c, r)]$ are independent of officer race, which is revealed to drivers in the model only after the decision over whether or not to carry drugs has been made; this independence is key to our identification strategy. ${ }^{9}$

In order to identify racial prejudice separately by officer race, we would ideally estimate the following fully-specified probit model:

$\operatorname{Pr}(\operatorname{search} \mid j, c, r)=H\left(\beta_{0}+\beta_{1} c+\beta_{2} 1[j=a]+\beta_{3} 1[r=a]+\beta_{4} 1[j=a, r=w]+\beta_{5} 1[j=w, r=a]\right)$,

Unfortunately, the parameters of this fully specified model cannot be estimated as the model is perfectly collinear. To see this, take the difference between the final two regressors:

$$
\Delta=1[j=a] \times 1[r=w]-1[j=w] \times 1[r=a]=1[j=a]-1[r=a]
$$

Thus, this difference $(\Delta)$ equals a linear combination of the first two regressors. Our inability to estimate this fully specified model is not surprising since, even if $c$ is a constant, there are only four possible cases of driver / officer interactions but five parameters. We can, however, feasibly estimate the following restricted model:

$$
\operatorname{Pr}(\operatorname{search} \mid j, c, r)=H\left(\beta_{0}+\beta_{1} c+\beta_{2} 1[j=a]+\beta_{3} 1[r=a]+\beta_{4} \text { mismatch }\right),
$$

where mismatch $=1[j=a, r=w]+1[j=w, r=a]$ indicates a traffic stop in which the race of the officer differs from the race of the driver. Given that we cannot identify racial prejudice separately for African-American and white officers, we assume that they are equally prejudiced $\left(t_{a}^{a}-t_{w}^{a}=t_{w}^{w}-t_{a}^{w}\right) \cdot{ }^{10}$ Under this assumption, we can write the following relationships between the theoretical and empirical specifications for this restricted model: ${ }^{11}$

\footnotetext{
${ }^{9}$ Drivers do, however, know the distribution of officer race, which is assumed to be the same for all motorists.

${ }^{10}$ If blacks and whites are not equally prejudiced, then our estimates will uncover the average level of prejudice across black and white officers.

${ }^{11}$ In order to derive these relationships, consider the following four possible cases of driver/officer interactions for both the theoretical and empirical models: 1) $j=w, r=w, 2) j=a, r=a, 3) j=w, r=a, 4$ ) $j=a, r=w$. One can then show that $\beta_{0}+\beta_{1} c=\pi(c, w)+t_{w}^{w}$. Using this relationship, the three key parameters can then be solved for.
} 


\section{RELATIONSHIP}

$\beta_{2}=t_{w}^{w}-t_{a}^{a}$

$\beta_{3}=\pi(c, a)-\pi(c, w)$

$\beta_{4}=t_{a}^{a}-t_{w}^{a}=t_{w}^{w}-t_{a}^{w}$

\section{INTERPRETATION}

Cost differences by officer race

Statistical discrimination

Racial prejudice

With data on the race of both the driver and the officer, we can thus distinguish between racial profiling based upon statistical discrimination, which is captured by the coefficient on driver race $\left(\beta_{3}\right)$, and racial profiling based upon prejudice, which is captured by the coefficient on mismatch $\left(\beta_{4}\right)$.

Consider next the case in which driver characteristics $(c)$ are unobserved to the econometrician. We show below that, under assumptions of normality and random matching of officers and drivers, our approach retains the ability to distinguish between racial prejudice and statistical discrimination even if unobserved driver characteristics are correlated with driver race. Intuitively, the coefficient on driver race absorbs any unobserved differences between black and white drivers, and the coefficient on mismatch is thus not contaminated by the presence of these unobserved characteristics.

Recall that, according to the probit model, officers search if the following expression holds:

$$
\beta_{0}+\beta_{1} c+\beta_{2} 1[j=a]+\beta_{3} 1[r=a]+\beta_{4} \text { mismatch }-U>0
$$

where $U \sim N(0,1)$. Assume next that unobserved driver characteristics are normally distributed with a mean that varies by race:

$$
c=c_{r}-\sigma \varepsilon, r=a, w
$$

where $\varepsilon \sim N(0,1)$ and is assumed to be independent of both driver race $(r)$ and officer characteristics $(U, j) .{ }^{12}$ As shown in Yatchew and Griliches (1985), without the normality assumption, which is made here for reasons of tractability, the presence of unobserved characteristics leads to complicated asymptomatic bias formulas in probit models. ${ }^{13}$ We refer

\footnotetext{
${ }^{12}$ The assumption that $c$ is a scalar is not crucial and can be generalized. In particular, allow an $N \times 1$ vector of unobserved driver characteristics $(C)$ to vary according to driver race and a random vector: $C=C_{r}-E$, where $C_{r}$ and $E$ are both $N \times 1$ vectors, and the components of $E$ are assumed to be distributed jointly normal with covariance matrix $\Sigma$. In this case, the unconditional probit can be written as follows:

$$
\operatorname{Pr}(\operatorname{search} \mid j, r)=H\left[\frac{\beta_{0}+\beta_{1} C_{w}+\beta_{2} 1[j=a]+\left[\beta_{3}+\beta_{1}\left(C_{a}-C_{w}\right)\right] 1[r=a]+\beta_{4} \text { mismatch }}{\sqrt{1+\beta_{1} \Sigma \beta_{1}^{\prime}}}\right]
$$

where $\beta_{1}$ is now a $1 \times N$ vector.

${ }^{13}$ In particular, the asymptotic bias formulas depend on the cumulative distribution function for unobserved
} 
to the assumption of independence between unobserved driver characteristics and mismatch as random matching. This random matching assumption will be satisfied if $\epsilon$ is uncorrelated with $j$ and $r$. We address the validity of this assumption in the empirical analysis to follow by studying how police officers are assigned to neighborhoods in Boston. ${ }^{14}$

Substituting in the above expression for unobserved driver characteristics, officers of race $j$ search drivers of race $r$ if:

$$
\beta_{0}+\beta_{1} c_{w}+\beta_{2} 1[j=a]+\left[\beta_{3}+\beta_{1}\left(c_{a}-c_{w}\right)\right] 1[r=a]+\beta_{4} \text { mismatch }-U-\sigma \beta_{1} \varepsilon>0
$$

Under the assumption that $U$ and $\varepsilon$ are independently distributed, $U-\sigma \beta_{1} \varepsilon \sim N\left(0,1+\beta_{1}^{2} \sigma^{2}\right)$ and the probability of search, unconditional on driver characteristics, is given as follows:

$$
\operatorname{Pr}(\operatorname{search} \mid j, r)=H\left[\frac{\beta_{0}+\beta_{1} c_{w}+\beta_{2} 1[j=a]+\left[\beta_{3}+\beta_{1}\left(c_{a}-c_{w}\right)\right] 1[r=a]+\beta_{4} \text { mismatch }}{\sqrt{1+\beta_{1}^{2} \sigma^{2}}}\right],
$$

We can thus define the unconditional probit parameters $\left(\gamma_{0}, \gamma_{2}, \gamma_{3}, \gamma_{4}\right)$ as follows:

$$
\begin{aligned}
\gamma_{0} & =\frac{\beta_{0}+\beta_{1} c_{w}}{\sqrt{1+\beta_{1}^{2} \sigma^{2}}} \\
\gamma_{2} & =\frac{\beta_{2}}{\sqrt{1+\beta_{1}^{2} \sigma^{2}}} \\
\gamma_{3} & =\frac{\beta_{3}+\beta_{1}\left(c_{a}-c_{w}\right)}{\sqrt{1+\beta_{1}^{2} \sigma^{2}}} \\
\gamma_{4} & =\frac{\beta_{4}}{\sqrt{1+\beta_{1}^{2} \sigma^{2}}}
\end{aligned}
$$

Using these definitions and the relationships listed above between the theoretical parameters and the probit parameters conditional on driver characteristics, we can thus relate the probit parameters unconditional on driver characteristics to the theoretical parameters as follows:

characteristics. Applying this lesson to our analysis, if traffic stops in which the race of the driver differs from the race of the officer are also stops in which drivers disproportionately carry drugs, then the coefficient on mismatch could be asympotically biased in either direction.

${ }^{14}$ Without the assumption of random matching, our empirical strategy no longer directly measures racial prejudice. Suppose, for example, that unobserved characteristics are correlated with mismatch so that $c=c_{r}+\eta$ mismatch $-\sigma \varepsilon$. In this case, the probit specification is given as follows:

$$
\operatorname{Pr}(\operatorname{search} \mid j, r)=H\left[\frac{\beta_{0}+\beta_{1} c_{w}+\beta_{2} 1[j=a]+\left[\beta_{3}+\beta_{1}\left(c_{a}-c_{w}\right)\right] 1[r=a]+\left(\beta_{4}+\beta_{1} \eta\right) \text { mismatch }}{\sqrt{1+\beta_{1}^{2} \sigma^{2}}}\right]
$$

Thus, the coefficient on mismatch will capture both racial prejudice $\left(\beta_{4}\right)$ and non-random matching $\left(\beta_{1} \eta\right)$. 


\section{RELATIONSHIP}

$\gamma_{2}=\left(t_{w}^{w}-t_{a}^{a}\right) / \sqrt{1+\beta_{1}^{2} \sigma^{2}}$

$\gamma_{3}=\left[\pi(c, a)-\pi(c, w)+\beta_{1}\left(c_{a}-c_{w}\right)\right] / \sqrt{1+\beta_{1}^{2} \sigma^{2}}$

$\gamma_{4}=\left(t_{a}^{a}-t_{w}^{a}\right) / \sqrt{1+\beta_{1}^{2} \sigma^{2}}=\left(t_{w}^{w}-t_{a}^{w}\right) / \sqrt{1+\beta_{1}^{2} \sigma^{2}} \quad$ Racial prejudice

\section{INTERPRETATION}

Cost differences by officer race

Statistical discrimination

These relationships yield several key insights. First, results from the case in which the econometrician observes and does not observe driver characteristics are identical if officers do not rely on driver characteristics in their search decisions $\left(\beta_{1}=0\right)$. In addition, if there is no heterogeneity other than race in unobserved characteristics $(\sigma=0)$, then the coefficients on officer race and mismatch are unchanged. The coefficient on driver race $\left(\gamma_{3}\right)$, however, is altered and now captures both statistical discrimination based purely upon race $[\pi(c, a)-\pi(c, w)]$ and statistical discrimination based upon driver characteristics that vary according to race $\left(\beta_{1}\left(c_{a}-c_{w}\right)\right)$; without further information, we cannot distinguish between these two forms of statistical discrimination. However, even if $\beta_{1} \neq 0$ and $\sigma \neq 0$, our approach retains the ability to distinguish between statistical discrimination, in whatever form it may take, and racial prejudice $\left(\gamma_{4}=\left(t_{a}^{a}-t_{w}^{a}\right) / \sqrt{1+\beta_{1}^{2} \sigma^{2}}\right)$. In fact, the presence of unobserved driver characteristics only serves to bias our analysis away from measuring racial prejudice due to the scaling factor $\left(\sqrt{1+\beta_{1}^{2} \sigma^{2}}\right)$, which exceeds one.

\section{Data}

In July 2000, the Massachusetts legislature passed Chapter 228 of the Acts of 2000, An Act Providing for the Collection of Data Relative to Traffic Stops. Among other things, this statute requires that, effective April 1, 2001, the Registry of Motor Vehicles collect data on the identifying characteristics of all individuals who receive a citation or who are arrested. The data collected by the State contain a wide variety of information including: the age, race and gender of the driver, the year, make and model of the car, the time, date and location of the stop, the alleged traffic infraction, whether a search was initiated and whether the stop resulted in an arrest.

The statute also required the Registry of Motor Vehicles to collect data on warnings. However, citing budgetary shortfalls, the Registry only compiled data on warnings for two months. Thus, for most of the time period under investigation, we do not observe stops for which an officer issued either a written or a verbal warning. That is, unless an officer issued a citation, the stop does not appear in our data outside of the two-month period. If officers 
favor members of their own racial group, then we might expect officers to issue citations to members of their own racial group only if they have committed relatively serious traffic infractions or if the officer strongly suspects that the driver is trafficking drugs. If so, then our estimates will tend to understate the extent of the racial bias in search patterns. We will address this data limitation later in the analysis by restricting our sample to the two-month period that includes data on warnings.

In addition to the citation-level data collected by the State, we were also able to obtain officer-level data from the Boston Police Department. These data contain, among other things, information on the officer's race, gender, rank and number of years on the force. For the subset of citations issued by officers in the Boston Police Department, we are then able to match the officer-level data to the citation-level data collected by the state. In total, we are able to match officer-level data to over 112,473 citations issued by 1,369 officers, representing just over 80 percent of the citations issued by officers in the Boston Police Department in our data. That is, for approximately 20 percent of the citations issued by an officer in the Boston Police Department in our data, we were unable to identify the officer who issued the citation.

We restrict our sample in a number of ways. First, we drop a small number of citations (6) for which contradictory race information was recorded. In addition, we drop citations issued by Asian officers (23 officers in total), and 8,051 citations issued to Asian, Native American and Middle Eastern motorists. As a result, all of the motorists and officers in our data are either black, white or Hispanic. Finally, we drop a small number of citations (10) that were issued to motorists outside the city of Boston in one of the surrounding suburbs. This may have happened, for example, if an officer followed a speeding driver outside of the city limits. Once these restrictions have been made we are left with 100,408 citations issued by 1,335 officers.

Of considerable concern is the fact that the search variable is missing for over 18 percent of the citations in our data. When filling out a citation, officers are required to check either "yes" or "no" to indicate whether a search was conducted. If an officer neglected to check either box, then the search variable is missing in our data. We do not know why officers failed to check this box. One possibility is that they were careless. Another is that they did not fully understand how to fill out the citation and generally only checked the "yes" box if they conducted a search but otherwise left the question blank. Interestingly, there is significant variation across officers in the proportion of citations for which the search variable is left missing; some officers appear to have been better at accurately filling out the citation 
than others. There are a number of ways of dealing with these missing values. We pick the method that we think is the best and then check to make sure that our results are robust to alternative procedures. In our baseline specification, if the officer indicated that a search was conducted for all citations in which search was non-missing, then we assume that if the search variable is missing, then no search was conducted. Then, we drop all officers for whom search is missing for more than 10 percent of the citations that those officers issue. Doing so eliminates approximately 25 percent of the citations (and 48 percent of the officers) in our data. For the remaining 684 officers, we drop observations for which search is missing, and are left with a sample comprising 72,903 citations. Tables 1 and 2 were calculated using our baseline search measure. In the next section, we discuss our robustness checks in greater detail.

Table 3 presents some basic summary statistics. The first column includes only those citations for which our baseline search measure is missing, whereas the second column includes only those citations for which our baseline search measure is available. Thus, comparing these first two columns provides some idea as to whether the citations for which search is missing differ systematically from those where it is not. Among citations for which search is missing, accidents are about twice as likely to have occurred as among citations for which search is not missing. There is also some variation across the first two columns in the percentage of citations that are issued in each neighborhood, reflecting the fact that officers in some districts were less likely to leave the search question blank than were officers in other districts. Otherwise, citations for which the search variable is missing appear to be quite similar to those for which it is not. ${ }^{15}$ The last three columns of Table 3 show the average characteristics of the citations in our sample broken down by the race of the officer issuing the citation. Interestingly, we see that officers disproportionately issue citations to motorists from their own racial group. As we will see below, this may reflect the fact that officers are more likely to issue tickets in districts in which a large portion of the population (and so, presumably, the drivers) are in the same racial group as the officer. Indeed, this is also reflected in the fact that there is variation across the last three columns in the proportion of citations issued in different neighborhoods. Finally, we see that black officers are more likely to issue citations at night and less likely to issue citations at which an accident has occurred than either white or Hispanic officers.

\footnotetext{
${ }^{15}$ We also estimated probit models for whether or not the search variable was missing as a function of officer and driver characteristics. The mismatch coefficient turns out to be negative but statistically insignificant. This insignificance suggests that the omission of missing observations is not driving our results. Even if the coefficient were statistically significant, this result would only serve to bias us against finding preference-based discrimination under the assumption that non-searches were more likely to be coded as missing observations. That is, our data are missing non-searches in which the race of the officer and driver were likely to match.
} 


\section{Search Patterns in the Boston Police Department}

In this section we test our model's theoretical predictions. For the time being we abstract from the possibility that there exist racial differences in officers' abilities to assess the guilt of motorists from different racial groups and the possibility that officers may be non-randomly matched with motorists from different racial groups.

We start by replicating the results presented in KPT. To do so, we use a probit model to study the probability of search and the probability of guilt conditional on search. In order to determine how the probability of search and the probability of guilt conditional on search differ depending on the race of the driver, we include indicator variables for whether the driver is black or Hispanic (so that white drivers are our omitted category). We also include as controls indicator variables for whether the stop occurred at night (6pm-5am), whether the driver was below the age of 25 , whether the driver was male, whether the driver was from in state, whether the driver was from in town and whether an accident had occurred. In addition, we include dummy variables that control for the district in which the stop occurred. In Table 4 (and in all remaining relevant tables) we report the estimated marginal impact of each variable on the probability of search. Column 1 presents the results from the probit model of the probability of search, and column 2 presents the results for the probability of guilt conditional on search. In these first two columns, each citation receives equal weight. However, concern that these results are driven by a small number of officers who issue an unusually large number of citations prompted us to repeat the analysis in columns 1 and 2 , but instead weight each citation by one over the number of citations given by the officer issuing that citation. The last two columns of Table 4 present the results of these weighted probits.

As will be seen, our results are sometimes sensitive to whether or not we weight citations in this fashion. In fact, the merits of weighting depend upon the question that you wish to answer. If you are interested in understanding the behavior of the average officer, the weighted probits provide a better description of the data since officers who issue a large number of tickets do not exert a disproportionate impact on the estimates. On the other hand, if you are interested in understanding search outcomes for the average motorist who receives a citation, then the unweighted probits are more appropriate. In this paper, we are interested in understanding the search decisions of officers and, in particular, whether

their behavior is consistent with preference-based discrimination. Thus, we believe that the results of the weighted probits are appropriate. For several reasons, however, we do present robustness checks using the unweighted probits. First, describing search outcomes 
for the average motorist is interesting in its own right. Second, differences between the weighted and unweighted probits, and the concomitant differences in the interpretation of the results, highlight the fact that citation-level data (even if officer race is available) may lead to misleading results if it is not possible to account for the fact that officers who issue a large number of tickets will be over-represented in the sample.

As the first column of the table indicates, black drivers are significantly more likely to have their cars searched than are white drivers. This result also holds for the weighted probit in column 3. In addition, like Knowles, Persico and Todd, we find no evidence that the probability of guilt conditional on search differs depending on the race of the driver. In particular, in both columns 2 and 4, the coefficient of the indicator variable for whether the driver is black is close to zero and not statistically different from zero. Table 5 is identical to Table 4 except that it drops citations for which either the officer or the driver was Hispanic. The results are very similar to those in Table 4.

KPT interpret the finding that the probability of guilt conditional on search is identical across racial groups as evidence against preference-based discrimination. However, as the discussion in the preceding section highlights, once the model of KPT is generalized to allow for heterogeneity in officer search costs, this prediction no longer holds.

However, our model delivers an alternative method for distinguishing between preferencebased discrimination and statistical discrimination. In particular, as discussed above, the model predicts that if statistical discrimination alone explains differences in the rate at which African-American and white drivers are pulled over, then there should be no difference in the rate at which officers from different racial groups search drivers from any given racial group. In order to determine how search patterns depend on the interaction between the race of the driver and the race of the officer, we again use a probit model to analyze the probability of search. Here, in addition to controlling for the race of the driver, we also include indicator variables for the race of the officer as well as an indicator variable that is equal to 1 if the race of the officer differs from the race of the driver (we call this indicator "mismatch"). Table 6 presents our results. In the first three columns, each citation receives equal weight, and each column includes a progressively broader set of controls. The last three columns are identical to the first three, except that in the last three columns each citation is weighted by one over the number of citations given by the officer issuing the citation. In all six columns, the coefficient on our mismatch indicator is positive and statistically different from zero at standard confidence levels. Thus, our results indicate that officers are more likely to search motorists who are not members of the officer's racial group. As mentioned before, this finding 
is inconsistent with standard models of statistical discrimination. In addition, our results also suggest that Hispanic officers are more likely to conduct searches than white officers, and the second and third columns suggest that officers are more likely to search motorists if they are black, young or involved in an accident. Table 7 presents the results from the same analysis as in Table 6 except that stops involving either Hispanic officers or Hispanic motorists are excluded from the sample. Again, in all six columns the coefficient estimate on the mismatch parameter is positive and significantly different from zero at standard confidence levels.

As mentioned previously, our estimates may be biased if the mismatch between the race of the officer and the race of the motorist is correlated with motorist characteristics $(c)$ that are not included in our regressions. Thus, it is comforting that the point estimate on mismatch changes very little as we add more regressors, suggesting that mismatch tends not to be correlated with unobserved motorist characteristics. We investigate this potential bias more fully below by empirically analyzing the assignment of officers to neighborhoods in Boston.

Note that a positive coefficient on our mismatch parameter could be driven, for example, by discrimination on the part of white officers against black drivers or by discrimination on the part of black officers against white drivers. As noted above, however, we cannot identify differences in racial prejudice by officer race. Thus, for example, our results should not be taken as evidence that black motorists in the Boston area are the subject to discrimination by officers in the Boston Police Department. Rather, our results simply indicate that the interaction between the race of the motorist and the race of the officer is significantly related to the probability that the motorist is searched, and we argue that this pattern is consistent with preference-based discrimination. ${ }^{16}$

As mentioned earlier, the search variable is missing for over 18 percent of the citations in our data. In order to make sure that our results are not sensitive to the way in which we treat these missing values, we conduct a number of robustness checks, the results of which are presented in Table 8. In the first column, we run the same basic specification as above with our full set of controls, but include in the analysis citations issued by officers for whom the search variable is missing in more than 10 percent of the citations issued by that officer. In the second column, we assume that if search was missing, then no search was conducted. The motivation for this assumption is the notion that officers may be more likely to leave the search question blank if no search was conducted. This obviously increases our sample size substantially. Finally, in column 3, we repeat the analysis in column 1 except that if

\footnotetext{
${ }^{16}$ Anwar and Fang (2004) apply a similar test to data from Florida and reach similar conclusions. Anwar and Fang base their test on a somewhat different theoretical model and the test that they propose is more stringent than the one we use here, but our conclusions would not change if we applied their test to our data.
} 
all of an officer's non-missing search citations indicate that a search was conducted, then we assume that no search was conducted for all of the missing observations. As shown, the point estimates drop in size relative to the comparable estimate using our baseline search measure. However, the mismatch coefficient remains statistically different from zero at the 99 percent confidence level.

Table 9 repeats the analysis in Table 8, except that it does not include stops that involve either Hispanic officers or Hispanic motorists. In all three columns, the coefficient on the mismatch indicator is positive and is statistically different from zero at standard confidence levels.

Recall that in our baseline search measure we drop officers for whom the search variable is missing for more than 10 percent of the citations issued by that officer. Although we do not present these results, we have also experimented with changing that 10 percent cutoff. Lowering the cutoff (to say 5 percent or 3 percent), tends to strengthen our results, while increasing the cutoff tends to weaken them. This is reflected in column 1 of Tables 8 and 9 where the cutoff is effectively 100 percent (all officers are included).

Approximately 82 percent of the officers in our data are patrol officers. The remaining officers are some manner of either Deputies, Detectives, Sergeants or Captains. We lack information on how an officer's duties vary according to his or her rank and, more importantly, we do not know how rank affects ticketing behavior (although it's clear that high-ranking officers issue fewer tickets). Thus, in Table 10, we repeat the analysis in Table 6, but restrict attention to citations that are issued by Patrol Officers. In all three columns, the coefficient on the mismatch indicator are positive, similar in magnitude to the comparable estimates in Table 6, and are statistically different from zero at standard levels. Table 11 repeats the analysis in Table 10 but excludes citations in which either the officer or the motorist is Hispanic. Again. the point estimates on the mismatch indicator are similar in magnitude to those in Table 7 , but are statistically different from zero (at the 90 percent confidence level) in only two out of the three columns. Overall, we take the results in Tables 10 and 11 as evidence that our results are not driven by idiosyncratic policing practices among higher-ranking officers.

As noted above, our data only include warnings for the two-month period of April-May 2001. In order to determine whether selection on the officer's decision to issue tickets or warnings is driving our findings of preference-based discrimination, we next restrict our sample to those stops within this two-month period. As shown in Table 12, the coefficient on the mismatch variable is larger than those in the baseline analysis in Table 6 . While the 
standard errors are also larger, probably reflecting the diminished sample size, the coefficients remain statistically significant at the 90 percent level. ${ }^{17}$ Taken together, these robustness checks demonstrate that our findings of preference-based discrimination are not driven by observations with missing search variables, patrol officer versus non-patrol officer distinctions, or selection on the officer's decision to issue warnings or tickets. In the remainder of the paper, we address other alternative explanations for our findings: informational asymmetries and the assignment of officers to neighborhoods.

\section{Asymmetric Search Ability}

One concern is that our results may be driven by the fact that officers may be more successful at finding drugs in cars that are driven by motorists who are in their own racial group. For example, Donohue and Levitt (2001) find evidence that own-race policing may be more efficient than cross-race policing. To see how this would affect our model, let $\phi_{r}^{j}$ denote the probability that an officer from group $j$ is successful of searching a motorist from group $r$; the baseline model is one in which this probability equals one for all officers and drivers. In this generalized model, the payoff to an officer from group $j$ to searching a motorist from group $r$ is given by

$$
\phi_{r}^{j} P(G \mid c, r)-t_{r}-U
$$

It should be clear from the above expression that the higher is $\phi_{r}^{j}$, the higher will be the benefit to officers from group $j$ of searching a motorist from group $r$. Thus, if officers are better at finding drugs when the motorist is a member of the officer's own racial group, then we would expect officers to be more likely to search motorists from their own racial group and our estimates will tend to understate the extent of preference-based discrimination. ${ }^{18}$ This result is shown graphically in Figure 7 .

In order to empirically address the possibility that asymmetric information drives our results, we examine whether our results hold among officers with more than 10 years of experience on the force. The hypothesis is that officers who have had substantial amounts of

\footnotetext{
${ }^{17}$ Although the results are not presented here, we also examined officer decisions over whether to issue warnings or tickets during this two-month period. Warnings were less likely to be issued if there was a mismatch between the race of the officer and the race of the driver, although this coefficient was statistically insignificant. As discussed earlier, however, this finding would only serve to bias our results against finding preference-based discrimination during the post-warnings period.

${ }^{18}$ Like Anwar and Fang (2004) and Bjerk (2004) we have also considered a model in which officers observe a noisy signal of a motorist's guilt that is unknown to motorists at the time they make their decision about whether to carry drugs, but that is correlated with the likelihood that they traffic drugs. One might expect officers to receive more informative signals from motorists who are in the officer's racial group than from those who are not. In an appendix available from the authors upon request, we show that changes in the information content of the signal deliver ambiguous predictions about search behavior.
} 
experience should be equally able to search the cars of motorists from different racial groups. The notion is that, officers become better at searching motorists from a particular group as exposure to that group increases. Thus, provided these improvements happen at a decreasing rate, experienced officers should be equally talented at searching motorists, irrespective of race.

Table 13 presents the results of our weighted probits; the first three columns focus on citations issued by officers with less than 10 years of experience while the last three columns focus on citations issued by officers with more than 10 years of experience. We chose 10 years of experience as our cutoff because it is close to the average experience level of officers in our data, approximately 12 years. However, our results are not sensitive to the exact cutoff experience level that we employ.

As shown, the coefficients on the mismatch indicator are small and statistically insignificant for inexperienced officers but large and statistically significant for experienced officers. Thus, these results suggests that our findings of preference-based discrimination are not driven by differences in the ability of officers to accurately search the cars of motorists from their own racial group. Rather, this analysis suggests that our results are stronger when we examine only experienced officers, for whom we would expect the likelihood of a successful search to be independent of the match between the officer's race and the driver's race.

\section{Unobserved Driver Characteristics and the Assignment of Officers to Neighborhoods}

As mentioned earlier, if there is some relevant characteristic, $c$, that is not included in our regressions and that is correlated with mismatch, then our estimate of $\beta_{4}$, the coefficient on mismatch, may be biased. One of the most plausible explanations for the source of this bias is that officers may not be randomly assigned to different neighborhoods within the city.

Suppose, for example, that white officers are disproportionately assigned to neighborhoods in which blacks commit a large fraction of the drug trafficking offenses. As a result, we would expect white officers to be more likely than black officers to search the cars of black motorists, even in the absence of preference-based discrimination. From a public relations perspective, it seems unlikely that officers would be assigned to neighborhoods in this fashion. Nonetheless, it is worth examining how the Department allocates officers across the city.

Officers in the Boston Police Department are assigned to one of 11 districts. These districts correspond to well-defined geographic areas within the city and are the primary organizational units for the Department. Figure 8 indicates both the name and location 
of these 11 districts. In addition, the Boston Police Department has a "Same Cop Same Neighborhood" (or "SC/SN") policing policy. Under SC/SN, patrol officers are assigned to a neighborhood beat within each district, and spend no less than 60 percent of their shift in that beat. The intent of SC/SN is to enable officers to become familiar with the local community to which they are assigned and, thus, be more effective at preventing crime. Unfortunately, while our data contain information on the district to which an officer was assigned at the time he or she issues a citation, we lack information on the officer's neighborhood beat.

In Table 14, we compare the racial composition of the population aged 18 and over in each district with the racial composition of the officers who are assigned to that district. As the table shows, in districts in which a relatively large percentage of the population is white, a relatively large proportion of the officers assigned to that district are white. Similarly, in districts in which a relatively large proportion of the population is black, a relatively large proportion of the officers assigned to that district is black, and the same pattern holds for Hispanics. For whites, the correlation between the fraction of the population aged 18 and older in each district who is white and the fraction of officers in that district who is white is 0.751. For blacks, Asian and Hispanics the analogous correlations are 0.844, 0.575 and 0.885, respectively. To some extent, these patterns may reflect intentional assignment patterns on the part of officials at the Boston Police Department. However, officers also have some discretion about the district to which they are assigned. In any case, officers appear to patrol areas in which the majority of residents are members of the officer's racial group.

However, even if officers tend to be assigned to districts in which the majority of residents are members of their own racial group, mismatch may be inherently correlated with the likelihood that the motorist is guilty. For example, if African-Americans go to predominantly white neighborhoods to sell drugs and if whites go to predominantly African-American neighborhoods to buy drugs ${ }^{19}$, then officers in predominantly white neighborhoods may deliberately target African-American motorists and officers in black predominantly black neighborhoods may deliberately target white motorists. As a result, a mismatch between the race of the motorist and the race of the officer may be correlated with the likelihood that a motorist is trafficking drugs.

In order to address this concern, Tables 15 and 16 provide results from only those traffic stops in which the motorist was a resident of the district in which he or she was pulled over. Presumably, when an officer stops a motorist, the officer can observe (by looking at the motorist's driver's license) whether the motorist is a resident of the district and, thus,

\footnotetext{
${ }^{19}$ Here we deliberately appeal to racial stereotypes about who buys and who sells drugs.
} 
whether he or she is a "suspicious outsider". As the Tables reveal, for all racial groups and for the sample that includes only African-Americans and whites, the coefficient on mismatch remains positive and is statistically different from zero in all six specifications. Thus, even if we focus on stops that take place in the district in which the motorist resides, we find that officers are more likely to conduct a search if the motorist is not a member of the officer's racial group.

In addition, in Tables 17 and 18, we break districts down into two categories: those that are racially diverse and those that are racially homogeneous. Using Table 14, we categorize East Boston, Roxbury/Mission Hill, Jamaica Plain and Hyde Park as diverse, while we categorize Boston Central (A-1 and D-4), South Boston, Allston/Brighton and West Roxbury/Roslindale as homogeneous. ${ }^{20}$ We drop citations that were issued in Dorchester and North Dorchester because these districts differ substantially in their racial composition and our data do not allow us to distinguish between the two. On balance, our results are somewhat stronger in racially homogeneous neighborhoods, suggesting that the police may target motorists whose race does not match the race of the average resident. However, even in the racially diverse districts the point estimate on the mismatch parameter is always positive and is statistically different from zero in three out of six specifications. The loss in power is likely to be driven by the reduced sample sizes when focusing on diverse districts.

Thus, Tables 14-18, provide evidence that our results are not driven by unobserved driver characteristics and the non-random assignment of officers to different districts within the city.

\section{Conclusion}

Between April 2001 and January 2003, over 43 percent of all searches conducted by officers from the Boston Police Department were of cars driven by African-American motorists even though cars driven by African-Americans made up less then 33 percent of the cars that were pulled over. One possible explanation for this discrepancy is statistical discrimination. Another is preference-based discrimination. In this paper, we develop a test that allows us to distinguish between these two hypotheses.

We start by generalizing the model of police search developed in Knowles, Persico and Todd (2001) to include heterogeneity in officer search costs; under this generalized model, the fundamental insight that allows KPT to distinguish between preference-based discrimination and statistical discrimination falls away. In particular, we show that even in the absence

\footnotetext{
${ }^{20}$ Charlestown in included in East Boston.
} 
of preference-based discrimination, there is no reason to expect the probability of guilt conditional on search to be the same across racial groups. However, we suggest an alternative test for distinguishing between statistical discrimination and preference-based discrimination. Our model predicts that if statistical discrimination alone accounts for racial disparities in the rate at which motorists from different racial groups are subject to search, then there should be no difference in the rate at which officers from different racial groups search drivers from any given group.

We test this hypothesis using data from the Boston Police Department. Our results strongly suggest that officers are more likely to conduct a search if the race of the motorist differs from the race of the officer. We then test whether this pattern could be explained by differences in the ability of officers from different racial groups to assess the guilt of motorists from a particular racial group. We find no evidence that this sort of informational asymmetry explains our results. We also show that the manner by which officers are assigned to neighborhoods within the city does not account for our empirical findings. Rather, our results suggest that preference-based discrimination plays a significant role in explaining differences in the rate at which motorists from different racial groups are searched during traffic stops. 


\section{References}

[1] Altonji, Joseph G. and Pierret, Charles R. "Employer Learning and Statistical Discrimination." Quarterly Journal of Economics, February 2001, 116(1), 313-350.

[2] Anwar, Shamena and Fang, Hanming "An Alternative Test of Racial Prejudice in Motor Vehicle Searches: Theory and Evidence." Mimeo, Yale University, June 2004.

[3] Arrow, Kenneth "The Theory of Discrimination," in O. Ashenfelter and A. Rees, eds., Discrimination in Labor Markets. Princeton, NJ: Princeton University Press, 1973, 3-33.

[4] Becker, Gary. The Economics of Discrimination. Chicago, IL: The University Chicago Press, 1957.

[5] Bjerk, David. "Racial Profiling, Statistical Discrimination, and the Effect of a Colorblind Policy on the Crime Rate." Mimeo, McMaster University, February 2004.

[6] Dedman, Bill and Latour, Francie. "Traffic Citations Reveal Disparity in Police Searches." The Boston Globe, January 6, 2003, pp.A1.

[7] Dedman, Bill and Latour, Francie. "Race, Sex and Age Drive Ticketing." The Boston Globe, July 20, 2003.

[8] Dedman, Bill and Latour, Francie. "Punishment Varies by Town and Officer." The Boston Globe, July 21, 2003.

[9] Dedman, Bill and Latour, Francie. "Troopers Fair, Tough in Traffic Encounters." The Boston Globe, July 22, 2003.

[10] Dharmapala, Dhammika and Ross, Stephen L. "Racial Bias in Motor Vehicle Searches: Additional Theory and Evidence." Forthcoming, Contributions to Economic Analysis and Policy, 2004.

[11] Dominitz, Jeff. "How Do the Laws of Probability Constrain Legislative and Judicial Efforts to Stop Racial Profiling?" American Law and Economic Review, August 2003, $5(2), 412-432$.

[12] Donohue, John J. and Levitt, Steven D. "The Impact of Race on Policing and Arrests." Journal of Law and Economics, October 2001, 44, 367-394.

[13] Harsanyi, J. "Games with Randomly Disturbed Payoffs: A New Rationale for Mixed Strategy Equilibrium Points." Internationl Journal of Game Theory 1973, 2, 1-23. 
[14] Hernández-Murillo, Ruben and Knowles, John. "Racial Profiling or Racist Policing?: Testing in Aggregated Data." Forthcoming, International Economic Review, 2004.

[15] Knowles, John; Persico Nicola; and Todd, Petra. "Racial Bias in Motor Vehicle Searches: Theory and Evidence." Journal of Political Economy, February 2001, 109 (11), 203-229.

[16] Yatchew, Adonis and Griliches, Zvi. "Specification Error in Probit Models." Review of Economic Studies, February 1985, 67(1), 134-39. 
Figure 1: Best Response Functions in KPT Model

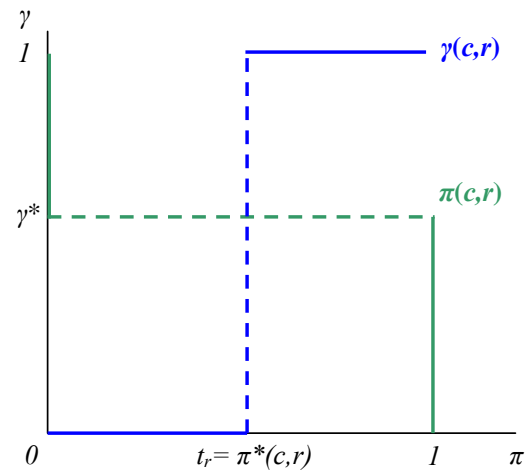

Figure 2: Best Response Functions with Motorist Heterogeneity

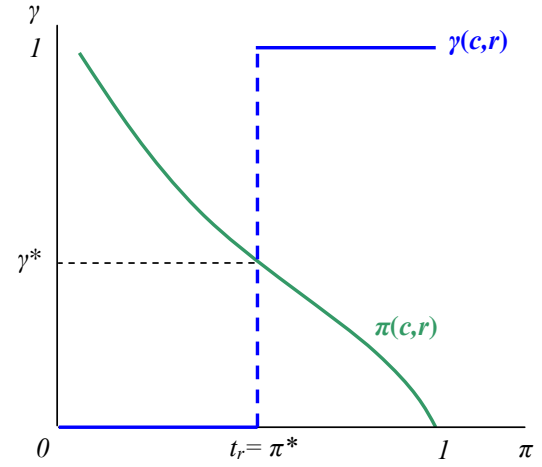

Figure 3: Preference-Based Discrimination in KPT Model

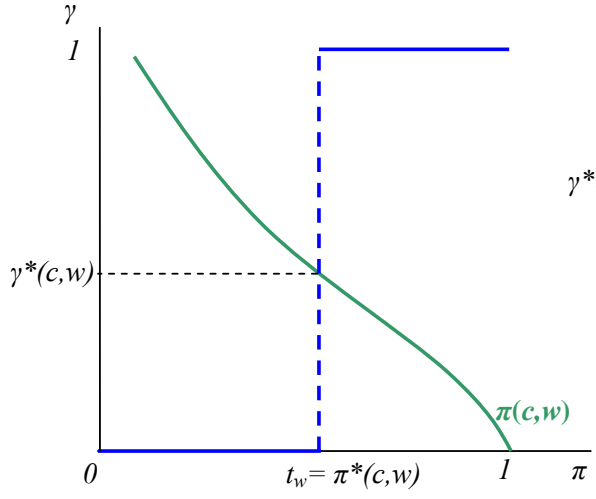

Whites

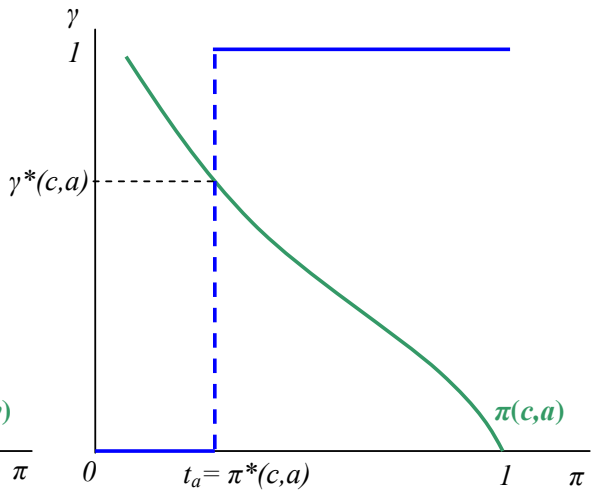

African-Americans 
Figure 4: Statistical Discrimination in KPT Model

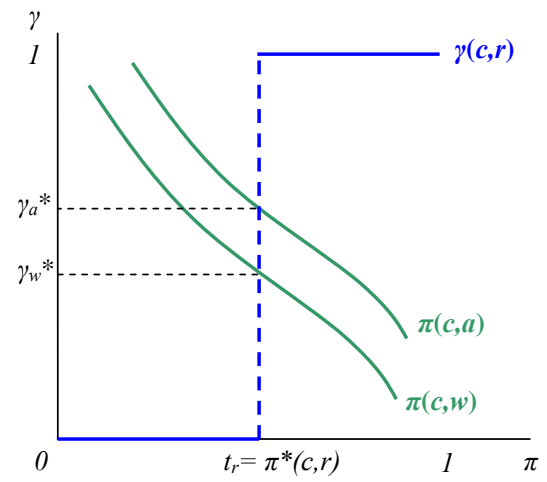

Figure 5: Statistical Discrimination with Officer Heterogeneity

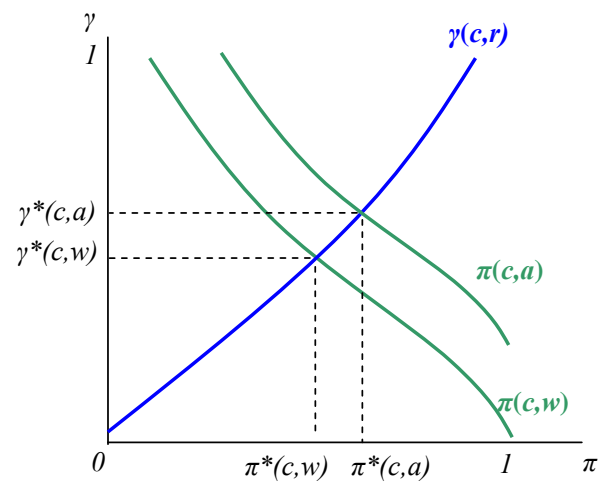

Figure 6: Preference-Based Discrimination with Officer Heterogeneity

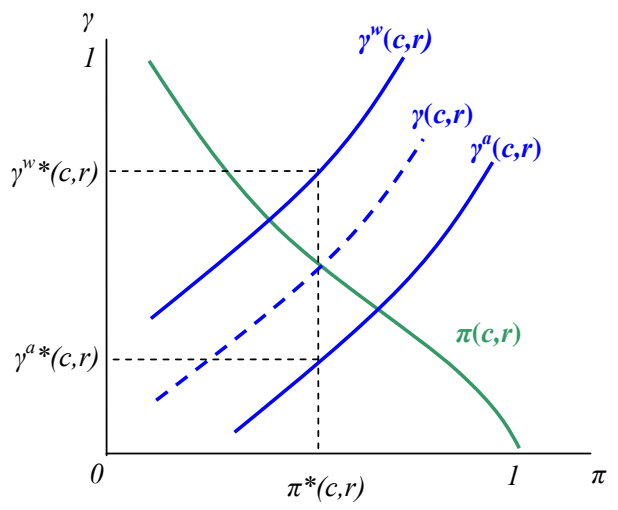


Figure 7: Asymmetric Search Ability

(Assumes $t_{r}^{w}=t_{r}^{a}$, but that $\phi_{w}^{w}>\phi_{w}^{a}$ )

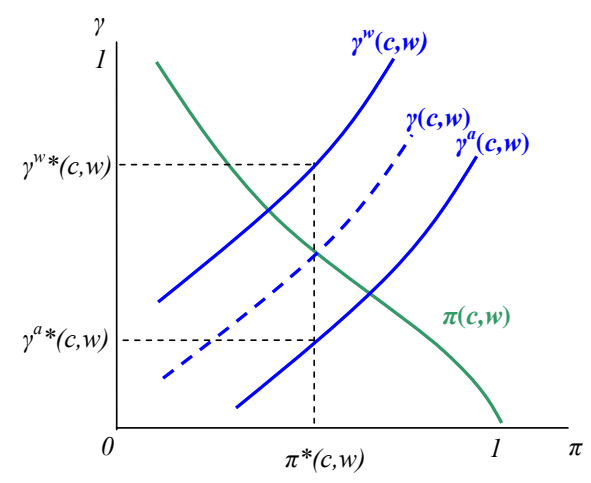

Figure 8: City of Boston, Police Districts

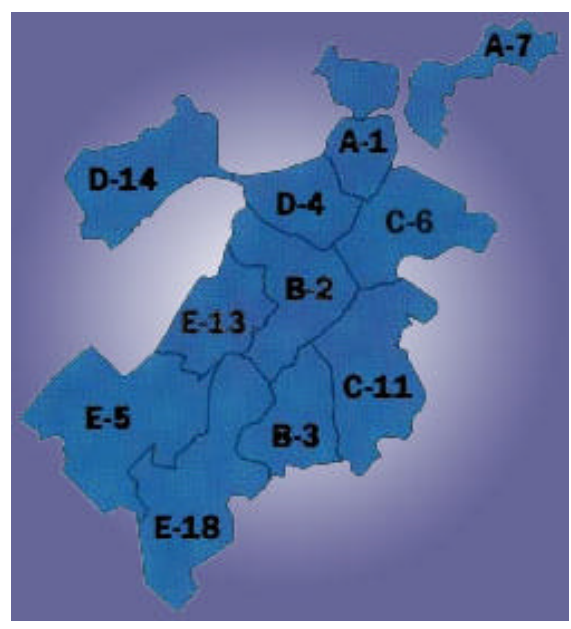
A-1 Downtown/Beacon Hill/Chinatown/Charlestown
A-7 East Boston
B-2 Roxbury/Mission Hill
B-3 Mattapan/North Dorchester
C-6 South Boston
C-11 Dorchester
D-4 Back Bay/Sound End/Fenway
D-14 Allston/Brighton
E-5 West Roxbury/Roslindale
E-13 Jamaica Plain
E-18 Hyde Park 
Table 1: Probability of Search by Officer Race and Driver Race (Standard Deviation of Sample Mean in Parentheses)

\begin{tabular}{|c|c|c|c|c|}
\hline \multirow[b]{2}{*}{ Driver Race } & \multicolumn{4}{|c|}{ Officer Race } \\
\hline & White & Black & Hispanic & All \\
\hline \multirow[t]{3}{*}{ White } & $0.41 \%$ & $0.67 \%$ & $0.24 \%$ & $0.47 \%$ \\
\hline & $(0.04 \%)$ & $(0.08 \%)$ & $(0.08 \%)$ & $(0.04 \%)$ \\
\hline & $n=23359$ & $n=11399$ & $\mathrm{n}=3370$ & $\mathrm{n}=38128$ \\
\hline \multirow[t]{3}{*}{ Black } & $1.00 \%$ & $0.81 \%$ & $0.47 \%$ & $0.88 \%$ \\
\hline & $(0.09 \%)$ & $(0.09 \%)$ & $(0.14 \%)$ & $(0.06 \%)$ \\
\hline & $\mathrm{n}=13533$ & $n=9326$ & $n=2339$ & $\mathrm{n}=25198$ \\
\hline \multirow[t]{3}{*}{ Hispanic } & $1.01 \%$ & $0.80 \%$ & $0.36 \%$ & $0.87 \%$ \\
\hline & $(0.14 \%)$ & $(0.16 \%)$ & $(0.18 \%)$ & $(0.09 \%)$ \\
\hline & $\mathrm{n}=5233$ & $n=3237$ & $\mathrm{n}=1105$ & $\mathrm{n}=9575$ \\
\hline \multirow[t]{3}{*}{ All } & $0.65 \%$ & $0.72 \%$ & $0.38 \%$ & $0.65 \%$ \\
\hline & $(0.04 \%)$ & $(0.05 \%)$ & $(0.07 \%)$ & $(0.03 \%)$ \\
\hline & $n=45755$ & $\mathrm{n}=25392$ & $\mathrm{n}=7181$ & $\mathrm{n}=78328$ \\
\hline
\end{tabular}

Note: Stops made by Asian officers are not inlcuded. Includes only officers for whom the search variable is missing for at most $10 \%$ of all citations. Stops involving drivers from other racial groups are included in the "All" category.

Table 2: Probability of Search by Officer Race and Driver Race Weighted by Inverse of Number of Citations

(Standard Deviation of Sample Mean in Parentheses)

\begin{tabular}{lcccc}
\hline & \multicolumn{4}{c}{ Officer Race } \\
\hline Driver Race & White & \multicolumn{1}{c}{ Black } & Hispanic & All \\
\hline White & $1.91 \%$ & $2.54 \%$ & $2.50 \%$ & $2.09 \%$ \\
& $(0.53 \%)$ & $(0.56 \%)$ & $(2.10 \%)$ & $(0.42 \%)$ \\
& $\mathrm{n}=404$ & $\mathrm{n}=139$ & $\mathrm{n}=46$ & $\mathrm{n}=589$ \\
& & & & \\
Black & $5.05 \%$ & $2.04 \%$ & $0.48 \%$ & $3.95 \%$ \\
& $(1.05 \%)$ & $(0.91 \%)$ & $(0.22 \%)$ & $(0.74 \%)$ \\
& $\mathrm{n}=364$ & $\mathrm{n}=137$ & $\mathrm{n}=42$ & $\mathrm{n}=543$ \\
& & & & \\
Hispanic & $4.89 \%$ & $4.55 \%$ & $0.28 \%$ & $4.34 \%$ \\
& $(1.64 \%)$ & $(2.43 \%)$ & $(0.16 \%)$ & $(1.23 \%)$ \\
& $\mathrm{n}=265$ & $\mathrm{n}=111$ & $\mathrm{n}=37$ & $\mathrm{n}=413$ \\
& & & & \\
All & $3.19 \%$ & $2.78 \%$ & $1.38 \%$ & $2.96 \%$ \\
& $(0.47 \%)$ & $(0.56 \%)$ & $(0.98 \%)$ & $(0.36 \%)$ \\
& $\mathrm{n}=473$ & $\mathrm{n}=164$ & $\mathrm{n}=52$ & $\mathrm{n}=689$ \\
& & & & \\
\hline
\end{tabular}

Note: Stops made by Asian officers are not inlcuded. Includes only officers for whom the search variable is missing for at most $10 \%$ of all citations. Stops involving drivers from other racial groups are included in the "All" category. For each officer, observations weighted by one over the number of citations given by that officer. 
Table 3: Summary Statistics

(Standard Deviation in Parentheses)

\begin{tabular}{|c|c|c|c|c|c|}
\hline \multirow{2}{*}{ Variable } & \multirow{2}{*}{$\begin{array}{c}\text { Baseline Search } \\
\text { Missing } \\
\text { All Officers }\end{array}$} & \multicolumn{4}{|c|}{ Primary Sample } \\
\hline & & All Officers & White Officers & Black Officers & Hispanic Officers \\
\hline \multirow[t]{2}{*}{ White Driver } & $56.7 \%$ & $52.3 \%$ & $55.5 \%$ & $47.6 \%$ & $49.5 \%$ \\
\hline & $(49.5 \%)$ & $(49.9 \%)$ & $(49.7 \%)$ & $(49.9 \%)$ & $(50.0 \%)$ \\
\hline \multirow[t]{2}{*}{ Black Driver } & $31.1 \%$ & $34.6 \%$ & $32.1 \%$ & $38.9 \%$ & $34.3 \%$ \\
\hline & $(46.3 \%)$ & $(47.6 \%)$ & $(46.7 \%)$ & $(48.8 \%)$ & $(47.5 \%)$ \\
\hline \multirow[t]{2}{*}{ Hispanic Driver } & $12.1 \%$ & $13.1 \%$ & $12.4 \%$ & $13.5 \%$ & $16.2 \%$ \\
\hline & $(32.7 \%)$ & $(33.8 \%)$ & $(33.0 \%)$ & $(34.2 \%)$ & $(36.9 \%)$ \\
\hline \multirow[t]{2}{*}{ Mismatch } & $49.4 \%$ & $53.6 \%$ & $44.5 \%$ & $61.1 \%$ & $83.8 \%$ \\
\hline & $(50.0 \%)$ & $(49.9 \%)$ & $(49.7 \%)$ & $(48.8 \%)$ & $(36.9 \%)$ \\
\hline \multirow[t]{2}{*}{ Baseline Search } & - & $0.7 \%$ & $0.7 \%$ & $0.7 \%$ & $0.3 \%$ \\
\hline & & $(8.1 \%)$ & $(8.2 \%)$ & $(8.6 \%)$ & $(36.9 \%)$ \\
\hline \multirow[t]{2}{*}{ Stop at Night } & $32.1 \%$ & $30.7 \%$ & $27.0 \%$ & $37.3 \%$ & $30.9 \%$ \\
\hline & $(46.7 \%)$ & $(46.1 \%)$ & $(44.4 \%)$ & $(48.4 \%)$ & $(46.2 \%)$ \\
\hline \multirow[t]{2}{*}{ Young Driver (Age<26) } & $25.0 \%$ & $24.3 \%$ & $24.2 \%$ & $23.8 \%$ & $26.3 \%$ \\
\hline & $(43.3 \%)$ & $(42.9 \%)$ & $(42.8 \%)$ & $(42.6 \%)$ & $(44.0 \%)$ \\
\hline \multirow[t]{2}{*}{ Male Driver } & $71.8 \%$ & $68.1 \%$ & $69.3 \%$ & $65.6 \%$ & $69.9 \%$ \\
\hline & $(45.0 \%)$ & $(46.6 \%)$ & $(46.1 \%)$ & $(47.5 \%)$ & $(45.9 \%)$ \\
\hline \multirow[t]{2}{*}{ In-State Driver } & $93.3 \%$ & $93.2 \%$ & $92.9 \%$ & $93.8 \%$ & $93.0 \%$ \\
\hline & $(25.0 \%)$ & $(25.2 \%)$ & $(25.8 \%)$ & $(24.2 \%)$ & $(25.4 \%)$ \\
\hline \multirow[t]{2}{*}{ In-Town Driver } & $49.2 \%$ & $51.1 \%$ & $49.1 \%$ & $54.3 \%$ & $52.5 \%$ \\
\hline & $(50.0 \%)$ & $(50.0 \%)$ & $(50.0 \%)$ & $(49.8 \%)$ & $(49.9 \%)$ \\
\hline \multirow[t]{2}{*}{ Accident } & $2.6 \%$ & $1.3 \%$ & $1.5 \%$ & $0.9 \%$ & $1.3 \%$ \\
\hline & $(15.8 \%)$ & $(11.3 \%)$ & $(12.1 \%)$ & $(9.7 \%)$ & $(11.5 \%)$ \\
\hline \multirow[t]{2}{*}{ Allston-Brighton } & $7.6 \%$ & $6.8 \%$ & $8.3 \%$ & $4.6 \%$ & $4.7 \%$ \\
\hline & $(26.5 \%)$ & $(25.1 \%)$ & $(27.6 \%)$ & $(21.0 \%)$ & $(21.1 \%)$ \\
\hline \multirow[t]{2}{*}{ Boston Central } & $19.9 \%$ & $13.1 \%$ & $12.8 \%$ & $12.2 \%$ & $18.1 \%$ \\
\hline & $(39.9 \%)$ & $(33.7 \%)$ & $(33.4 \%)$ & $(32.7 \%)$ & $(38.5 \%)$ \\
\hline \multirow[t]{2}{*}{ Charlestown-East Boston } & $10.1 \%$ & $6.2 \%$ & $8.4 \%$ & $3.2 \%$ & $3.2 \%$ \\
\hline & $(30.2 \%)$ & $(24.1 \%)$ & $(27.8 \%)$ & $(17.5 \%)$ & $(17.5 \%)$ \\
\hline \multirow[t]{2}{*}{ Dorchester-Mattapan } & $21.4 \%$ & $19.9 \%$ & $20.3 \%$ & $20.1 \%$ & $16.4 \%$ \\
\hline & $(41.0 \%)$ & $(39.9 \%)$ & $(40.2 \%)$ & $(40.1 \%)$ & $(37.0 \%)$ \\
\hline \multirow[t]{2}{*}{ Hyde Park } & $0.7 \%$ & $0.9 \%$ & $0.7 \%$ & $1.3 \%$ & $0.5 \%$ \\
\hline & $(8.4 \%)$ & $(9.3 \%)$ & $(8.3 \%)$ & $(11.4 \%)$ & $(6.7 \%)$ \\
\hline \multirow[t]{2}{*}{ Jamaica Plain } & $2.3 \%$ & $2.5 \%$ & $3.1 \%$ & $0.4 \%$ & $6.1 \%$ \\
\hline & $(14.9 \%)$ & $(15.6 \%)$ & $(17.3 \%)$ & $(6.2 \%)$ & $(23.9 \%)$ \\
\hline \multirow[t]{2}{*}{ Roslindale } & $0.5 \%$ & $1.1 \%$ & $1.3 \%$ & $1.1 \%$ & $0.7 \%$ \\
\hline & $(7.2 \%)$ & $(10.6 \%)$ & $(11.2 \%)$ & $(10.2 \%)$ & $(8.2 \%)$ \\
\hline \multirow[t]{2}{*}{ Roxbury } & $13.3 \%$ & $17.5 \%$ & $18.5 \%$ & $15.2 \%$ & $19.7 \%$ \\
\hline & $(33.9 \%)$ & $(38.0 \%)$ & $(38.9 \%)$ & $(35.9 \%)$ & $(39.8 \%)$ \\
\hline \multirow[t]{2}{*}{ South Boston } & $6.0 \%$ & $4.0 \%$ & $4.6 \%$ & $3.5 \%$ & $1.8 \%$ \\
\hline & $(23.7 \%)$ & $(19.6 \%)$ & $(21.0 \%)$ & $(18.4 \%)$ & $(13.2 \%)$ \\
\hline Number of Officers & 946 & 684 & 469 & 163 & 52 \\
\hline Number of Citations & 27,505 & 72,903 & 42,125 & 23,964 & 6,814 \\
\hline
\end{tabular}


Table 4: Probability of Search and Guilt Conditional on Search Officer Race Excluded

\begin{tabular}{lcccc}
\hline & \multicolumn{2}{c}{ Unweighted Probits } & \multicolumn{2}{c}{ Weighted Probits } \\
\hline & Search & Guilt & Search & Guilt \\
\hline Black Driver & $0.003^{* * *}$ & -0.001 & $0.019^{* *}$ & -0.001 \\
& $(0.001)$ & $(0.001)$ & $(0.010)$ & $(0.002)$ \\
Hispanic Driver & 0.003 & -0.000 & 0.015 & 0.003 \\
& $(0.002)$ & $(0.000)$ & $(0.013)$ & $(0.005)$ \\
Stop at Night & 0.002 & 0.000 & 0.013 & -0.001 \\
& $(0.002)$ & $(0.000)$ & $(0.008)$ & $(0.001)$ \\
Young Driver (Age<26) & $0.001^{* *}$ & -0.000 & 0.006 & -0.002 \\
& $(0.001)$ & $(0.000)$ & $(0.008)$ & $(0.001)$ \\
Male Driver & 0.001 & -0.000 & 0.006 & -0.005 \\
& $(0.001)$ & $(0.000)$ & $(0.006)$ & $(0.007)$ \\
In-State Driver & 0.001 & & 0.010 & \\
In-Town Driver & $(0.001)$ & & $(0.007)$ & \\
& 0.000 & -0.000 & 0.003 & 0.001 \\
Accident & $(0.001)$ & $(0.000)$ & $(0.006)$ & $(0.001)$ \\
& $0.037^{* *}$ & -0.000 & -0.000 & -0.001 \\
Neighborhood Control & $(0.015)$ & $(0.000)$ & $(0.011)$ & $(0.001)$ \\
Observations & YES & YES & YES & YES \\
\hline Robust standard errors in parentheses & 363 \\
\hline
\end{tabular}

Robust standard errors in parentheses

$*$ significant at $10 \%$; ** significant at $5 \%$; *** significant at $1 \%$

If the search outcomes for an officer are missing in all cases except those in which the officer indicates that a search was conducted, then we code the missing search outcomes as "no search" (this affects 33 citations). After this correction, officers with missing values for more than $10 \%$ of search outcomes are dropped. Missing search outcomes for the remaining officers are dropped.

Table 5: Probability of Search and Guilt Conditional on Search Officer Race Excluded, Blacks and Whites Only

\begin{tabular}{lcccc}
\hline & \multicolumn{2}{c}{ Unweighted Probits } & \multicolumn{2}{c}{ Weighted Probits } \\
\hline Black Driver & Search & Guilt & Search & Guilt \\
& $0.003^{* *}$ & -0.014 & $0.018^{*}$ & -0.013 \\
Stop at Night & $(0.001)$ & $(0.014)$ & $(0.010)$ & $(0.012)$ \\
& 0.002 & 0.003 & 0.012 & 0.010 \\
Young Driver (Age<26) & $(0.002)$ & $(0.011)$ & $(0.009)$ & $(0.007)$ \\
& 0.001 & -0.011 & 0.005 & $-0.015^{*}$ \\
Male Driver & $(0.001)$ & $(0.009)$ & $(0.009)$ & $(0.008)$ \\
& 0.001 & -0.014 & 0.003 & -0.031 \\
In-State Driver & $(0.001)$ & $(0.012)$ & $(0.007)$ & $(0.023)$ \\
& -0.000 & & 0.007 & \\
In-Town Driver & $(0.001)$ & & $(0.009)$ & \\
& $0.001^{*}$ & -0.001 & 0.006 & 0.001 \\
Accident & $(0.001)$ & $(0.009)$ & $(0.008)$ & $(0.005)$ \\
& $0.043^{* *}$ & -0.002 & 0.002 & $-0.005^{*}$ \\
Neighborhood Controls & $(0.018)$ & $(0.011)$ & $(0.014)$ & $(0.003)$ \\
Observations & YES & YES & YES & YES \\
\hline Robust standar & 55824 & 329 & 55824 & 329 \\
\hline
\end{tabular}

Robust standard errors in parentheses .

* significant at $10 \%$; * significant at $5 \%$; *** significant at $1 \%$

If the search outcomes for an officer are missing in all cases except those in which the officer indicates that a search was conducted, then we code the missing search outcomes as "no search" (this affects 33 citations). After this correction, officers with missing values for more than $10 \%$ of search outcomes are dropped. Missing search outcomes for the remaining officers are dropped. 
Table 6: Probability of Search, Baseline Specification

\begin{tabular}{|c|c|c|c|c|c|c|}
\hline & \multicolumn{3}{|c|}{ Unweighted Probits } & \multicolumn{3}{|c|}{ Weighted Probits } \\
\hline & $(1)$ & (2) & (3) & (4) & (5) & (6) \\
\hline \multirow[t]{2}{*}{ Black Driver } & $0.004 * * *$ & $0.003 * *$ & $0.003 * *$ & 0.008 & 0.003 & 0.006 \\
\hline & $(0.001)$ & $(0.001)$ & $(0.001)$ & $(0.009)$ & $(0.007)$ & $(0.008)$ \\
\hline \multirow[t]{2}{*}{ Hispanic Driver } & 0.003 & 0.002 & 0.001 & 0.004 & 0.000 & -0.001 \\
\hline & $(0.003)$ & $(0.002)$ & $(0.002)$ & $(0.012)$ & $(0.011)$ & $(0.010)$ \\
\hline \multirow[t]{2}{*}{ Black Officer } & 0.001 & 0.001 & 0.001 & -0.007 & -0.009 & -0.007 \\
\hline & $(0.003)$ & $(0.003)$ & $(0.003)$ & $(0.008)$ & $(0.007)$ & $(0.007)$ \\
\hline \multirow[t]{2}{*}{ Hispanic Officer } & $-0.004 *$ & $-0.003^{*}$ & -0.003 & $-0.019 * *$ & $-0.018 * *$ & $-0.016^{* *}$ \\
\hline & $(0.002)$ & $(0.002)$ & $(0.002)$ & $(0.009)$ & $(0.008)$ & $(0.007)$ \\
\hline \multirow[t]{2}{*}{ Mismatch } & $0.002 * *$ & $0.002^{*}$ & $0.002^{* *}$ & $0.019 * *$ & $0.023 * * *$ & $0.020 * * *$ \\
\hline & $(0.001)$ & $(0.001)$ & $(0.001)$ & $(0.009)$ & $(0.007)$ & $(0.006)$ \\
\hline \multirow[t]{2}{*}{ Stop at Night } & & 0.002 & 0.002 & & 0.014 & 0.013 \\
\hline & & $(0.002)$ & $(0.002)$ & & $(0.009)$ & $(0.008)$ \\
\hline \multirow[t]{2}{*}{ Young Driver $($ Age <26) } & & $0.002 * *$ & $0.002 * *$ & & 0.006 & 0.006 \\
\hline & & $(0.001)$ & $(0.001)$ & & $(0.008)$ & $(0.007)$ \\
\hline \multirow[t]{2}{*}{ Male Driver } & & 0.001 & 0.001 & & 0.006 & 0.005 \\
\hline & & $(0.001)$ & $(0.001)$ & & $(0.006)$ & $(0.006)$ \\
\hline \multirow[t]{2}{*}{ In-State Driver } & & 0.002 & 0.001 & & 0.011 & 0.010 \\
\hline & & $(0.001)$ & $(0.001)$ & & $(0.007)$ & $(0.007)$ \\
\hline \multirow[t]{2}{*}{ In-Town Driver } & & 0.000 & 0.000 & & -0.000 & 0.002 \\
\hline & & $(0.001)$ & $(0.001)$ & & $(0.006)$ & $(0.006)$ \\
\hline \multirow[t]{2}{*}{ Accident } & & $0.039 * * *$ & $0.037 * *$ & & 0.000 & -0.001 \\
\hline & & $(0.014)$ & $(0.015)$ & & $(0.011)$ & $(0.011)$ \\
\hline Neighborhood Controls & NO & NO & YES & NO & NO & YES \\
\hline Observations & 72903 & 70614 & 70614 & 72903 & 70614 & 70614 \\
\hline
\end{tabular}

Robust standard errors in parentheses

$*$ significant at $10 \% ; * *$ significant at $5 \%$;*** significant at $1 \%$

Table 7: Probability of Search, Baseline Specification Blacks and Whites Only

\begin{tabular}{|c|c|c|c|c|c|c|}
\hline & \multicolumn{3}{|c|}{ Unweighted Probits } & \multicolumn{3}{|c|}{ Weighted Probits } \\
\hline & (1) & (2) & (3) & (4) & (5) & (6) \\
\hline \multirow[t]{2}{*}{ Black Driver } & $0.004 * *$ & $0.003 *$ & $0.002 * *$ & 0.011 & 0.004 & 0.004 \\
\hline & $(0.001)$ & $(0.001)$ & $(0.001)$ & $(0.010)$ & $(0.007)$ & $(0.008)$ \\
\hline \multirow[t]{2}{*}{ Black Officer } & 0.001 & 0.001 & 0.001 & -0.008 & -0.012 & $-0.011^{*}$ \\
\hline & $(0.003)$ & $(0.003)$ & $(0.003)$ & $(0.009)$ & $(0.007)$ & $(0.007)$ \\
\hline \multirow[t]{2}{*}{ Mismatch } & $0.002 *$ & $0.002 *$ & $0.002 *$ & $0.017 *$ & $0.022 * * *$ & $0.021 * * *$ \\
\hline & $(0.001)$ & $(0.001)$ & $(0.001)$ & $(0.010)$ & $(0.008)$ & $(0.007)$ \\
\hline \multirow[t]{2}{*}{ Stop at Night } & & 0.002 & 0.002 & & 0.012 & 0.012 \\
\hline & & $(0.002)$ & $(0.002)$ & & $(0.009)$ & $(0.009)$ \\
\hline \multirow[t]{2}{*}{ Young Driver $($ Age $<26)$} & & 0.001 & 0.001 & & 0.004 & 0.004 \\
\hline & & $(0.001)$ & $(0.001)$ & & $(0.009)$ & $(0.008)$ \\
\hline \multirow[t]{2}{*}{ Male Driver } & & 0.001 & 0.001 & & 0.002 & 0.001 \\
\hline & & $(0.001)$ & $(0.001)$ & & $(0.007)$ & $(0.007)$ \\
\hline \multirow[t]{2}{*}{ In-State Driver } & & 0.000 & -0.000 & & 0.006 & 0.007 \\
\hline & & $(0.001)$ & $(0.001)$ & & $(0.009)$ & $(0.008)$ \\
\hline \multirow[t]{2}{*}{ In-Town Driver } & & $0.001^{*}$ & $0.001 *$ & & 0.005 & 0.006 \\
\hline & & $(0.001)$ & $(0.001)$ & & $(0.007)$ & $(0.007)$ \\
\hline \multirow[t]{2}{*}{ Accident } & & $0.043 * *$ & $0.043 * *$ & & 0.003 & 0.002 \\
\hline & & $(0.018)$ & $(0.019)$ & & $(0.014)$ & $(0.013)$ \\
\hline Neighborhood Controls & NO & NO & YES & NO & NO & YES \\
\hline Observations & 57621 & 55824 & 55824 & 57621 & 55824 & 55824 \\
\hline
\end{tabular}

Robust standard errors in parentheses

* significant at $10 \%$;** significant at $5 \%$; *** significant at $1 \%$ 
Table 8: Probability of Search, Robustness Checks

\begin{tabular}{lccc}
\hline & \multicolumn{3}{c}{ Weighted Probits } \\
\hline Black Driver & Search 1 & Search 2 & Search 3 \\
& $0.011^{*}$ & 0.008 & $0.011^{*}$ \\
Hispanic Driver & $(0.007)$ & $(0.005)$ & $(0.007)$ \\
& 0.003 & 0.002 & 0.003 \\
Black Officer & $(0.008)$ & $(0.006)$ & $(0.008)$ \\
& -0.005 & -0.004 & -0.005 \\
Hispanic Officer & $(0.006)$ & $(0.004)$ & $(0.006)$ \\
& -0.010 & $-0.009^{*}$ & -0.010 \\
Mismatch & $(0.007)$ & $(0.005)$ & $(0.007)$ \\
& $0.014^{* * *}$ & $0.011^{* * *}$ & $0.014^{* * *}$ \\
Stop at Night & $(0.005)$ & $(0.004)$ & $(0.005)$ \\
& $0.014^{* *}$ & $0.010^{* *}$ & $0.014 * *$ \\
Young Driver (Age<26) & $(0.006)$ & $(0.004)$ & $(0.006)$ \\
& 0.008 & 0.006 & 0.008 \\
Male Driver & $(0.006)$ & $(0.004)$ & $(0.006)$ \\
& $0.010^{* *}$ & $0.007 * *$ & $0.010^{* *}$ \\
In-State Driver & $(0.005)$ & $(0.003)$ & $(0.005)$ \\
In-Town Driver & 0.007 & 0.006 & 0.008 \\
& $(0.007)$ & $(0.005)$ & $(0.006)$ \\
Accident & 0.004 & 0.001 & 0.004 \\
& $(0.005)$ & $(0.004)$ & $(0.005)$ \\
Neighborhood Controls & 0.001 & -0.000 & 0.001 \\
Observations & $(0.009)$ & $(0.006)$ & $(0.009)$ \\
\hline Robust & YES & YES & YES \\
& 79,337 & 95,855 & 79,369 \\
\hline
\end{tabular}

Robust standard errors in parentheses

* significant at $10 \%$; * significant at $5 \%$; *** significant at $1 \%$

Table 9: Probability of Search, Robustness Checks Blacks and Whites Only

\begin{tabular}{|c|c|c|c|}
\hline & \multicolumn{3}{|c|}{ Weighted Probits } \\
\hline & Search 1 & Search 2 & Search 3 \\
\hline \multirow[t]{2}{*}{ Black Driver } & 0.010 & 0.007 & 0.009 \\
\hline & $(0.007)$ & $(0.005)$ & $(0.007)$ \\
\hline \multirow[t]{2}{*}{ Black Officer } & $-0.010^{*}$ & $-0.007 *$ & $-0.010 *$ \\
\hline & $(0.006)$ & $(0.004)$ & $(0.006)$ \\
\hline \multirow[t]{2}{*}{ Mismatch } & $0.014 * *$ & $0.011 * *$ & $0.014 * *$ \\
\hline & $(0.006)$ & $(0.005)$ & $(0.006)$ \\
\hline \multirow[t]{2}{*}{ Stop at Night } & $0.011^{*}$ & 0.008 & $0.011^{*}$ \\
\hline & $(0.007)$ & $(0.005)$ & $(0.007)$ \\
\hline \multirow[t]{2}{*}{ Young Driver $($ Age $<26)$} & 0.006 & 0.004 & 0.006 \\
\hline & $(0.006)$ & $(0.005)$ & $(0.006)$ \\
\hline \multirow[t]{2}{*}{ Male Driver } & 0.007 & 0.005 & 0.007 \\
\hline & $(0.005)$ & $(0.004)$ & $(0.005)$ \\
\hline \multirow[t]{2}{*}{ In-State Driver } & 0.003 & 0.002 & 0.003 \\
\hline & $(0.008)$ & $(0.006)$ & $(0.008)$ \\
\hline \multirow[t]{2}{*}{ In-Town Driver } & 0.005 & 0.002 & 0.005 \\
\hline & $(0.006)$ & $(0.004)$ & $(0.006)$ \\
\hline \multirow[t]{2}{*}{ Accident } & -0.002 & -0.003 & -0.002 \\
\hline & $(0.010)$ & $(0.006)$ & $(0.010)$ \\
\hline Neighborhood Controls & YES & YES & YES \\
\hline Observations & 62,539 & 74,837 & 62,560 \\
\hline
\end{tabular}


Table 10: Probability of Search, Patrol Officers

\begin{tabular}{lccc}
\hline & \multicolumn{3}{c}{ Weighted Probits } \\
\hline Black Driver & $(1)$ & $(2)$ & $(3)$ \\
& $(0.005$ & -0.002 & 0.003 \\
Hispanic Driver & 0.001 & $(0.008)$ & $(0.008)$ \\
& $(0.011)$ & 0.003 & 0.001 \\
Black Officer & -0.012 & $(0.011)$ & $(0.009)$ \\
& $(0.008)$ & -0.009 & -0.007 \\
Hispanic Officer & $-0.018^{* *}$ & $-0.008)$ & $(0.007)$ \\
& $(0.009)$ & $(0.009)$ & $-0.013^{*}$ \\
Mismatch & $0.016^{* *}$ & $0.016^{* *}$ & $(0.008)$ \\
& $(0.008)$ & $(0.008)$ & $0.013^{* *}$ \\
Stop at Night & & 0.009 & $0.006)$ \\
& & $(0.009)$ & 0.007 \\
Young Driver (Age<26) & & -0.004 & $-0.007)$ \\
& & $(0.007)$ & $(0.006)$ \\
Male Driver & & 0.008 & 0.007 \\
& & $(0.006)$ & $(0.005)$ \\
In-State Driver & & 0.008 & 0.007 \\
In-Town Driver & & $(0.008)$ & $(0.007)$ \\
& & -0.002 & -0.000 \\
Accident & & $(0.006)$ & $(0.006)$ \\
Neighborhood Controls & & 0.018 & 0.017 \\
Observations & & $(0.018)$ & $(0.018)$ \\
\hline Robust & & NO & YES \\
& 71,560 & 69,346 & 69,346 \\
\hline
\end{tabular}

Robust standard errors in parentheses

$*$ significant at $10 \%$; * significant at $5 \%$; *** significant at $1 \%$

Table 11: Probability of Search, Patrol Officers Blacks and Whites Only

\begin{tabular}{lccc}
\hline & \multicolumn{3}{c}{ Weighted Probits } \\
\hline Black Driver & $(1)$ & $(2)$ & $(3)$ \\
& -0.001 & 0.001 & 0.005 \\
Black Officer & $(0.008)$ & $(0.008)$ & $(0.009)$ \\
& -0.010 & -0.007 & -0.007 \\
Mismatch & $(0.008)$ & $(0.008)$ & $(0.007)$ \\
& 0.014 & $0.013^{*}$ & $0.013^{*}$ \\
Stop at Night & $(0.009)$ & $(0.008)$ & $(0.007)$ \\
& & 0.009 & 0.008 \\
Young Driver (Age<26) & $(0.010)$ & $(0.009)$ \\
& & $-0.010^{*}$ & -0.009 \\
Male Driver & & $(0.006)$ & $(0.006)$ \\
& & 0.004 & 0.004 \\
In-State Driver & & $(0.007)$ & $(0.006)$ \\
& & 0.002 & 0.003 \\
In-Town Driver & & $(0.009)$ & $(0.008)$ \\
Accident & & 0.000 & 0.000 \\
& & $(0.007)$ & $(0.008)$ \\
Neighborhood Controls & & 0.028 & 0.028 \\
Observations & NO & $(0.024)$ & $(0.023)$ \\
\hline Robust standard errors in parentheses & NO & YES \\
$*$ significant at 10\%; $* *$ significant at 5\%; *** significant at 1\% & \\
& & & 54,684 \\
\hline
\end{tabular}


Table 12: Probability of Search, April-May 2001

\begin{tabular}{lccc}
\hline & \multicolumn{3}{c}{ Weighted Probits } \\
\hline Black Driver & $(1)$ & $(2)$ & $(3)$ \\
& -0.016 & -0.014 & $-0.015^{*}$ \\
Hispanic Driver & $(0.015)$ & $(0.011)$ & $(0.009)$ \\
& 0.017 & 0.011 & -0.003 \\
Black Officer & $(0.027)$ & $(0.022)$ & $(0.014)$ \\
& 0.005 & 0.003 & 0.009 \\
Hispanic Officer & $(0.017)$ & $(0.014)$ & $(0.015)$ \\
& -0.004 & 0.004 & -0.003 \\
Mismatch & $(0.026)$ & $(0.024)$ & $(0.016)$ \\
& $0.030^{*}$ & $0.028^{*}$ & $0.030^{*} *$ \\
Stop at Night & $(0.018)$ & $(0.016)$ & $(0.013)$ \\
& & 0.030 & $0.031^{*}$ \\
Young Driver (Age<26) & $(0.021)$ & $(0.017)$ \\
& & -0.009 & $-0.012^{*}$ \\
Male Driver & & $(0.010)$ & $(0.007)$ \\
& & $0.022^{* *}$ & $0.017^{*} *$ \\
In-State Driver & & $(0.011)$ & $(0.008)$ \\
In-Town Driver & & 0.012 & 0.008 \\
& & $(0.011)$ & $(0.010)$ \\
Accident & & -0.004 & -0.001 \\
Neighborhood Controls & & $(0.010)$ & $(0.008)$ \\
Observations & & 0.010 & 0.010 \\
\hline Robust Stand & $(0.023)$ & $(0.024)$ \\
& & NO & YES \\
& 16,162 & 15,407 & 13,683 \\
\hline
\end{tabular}

Robust standard errors in parentheses

$*$ significant at $10 \%$; ** significant at $5 \%$; *** significant at $1 \%$

Table 13: Probability of Search, Unexperienced vs. Experienced Officers Weighted Probits

\begin{tabular}{|c|c|c|c|c|c|c|}
\hline & \multicolumn{3}{|c|}{ Inexperienced Officers $(<=10$ years $)$} & \multicolumn{3}{|c|}{ Experienced Officers (>10 years) } \\
\hline & (1) & $(2)$ & (3) & (4) & (5) & (6) \\
\hline \multirow[t]{2}{*}{ Black Driver } & -0.008 & -0.004 & -0.002 & 0.024 & 0.007 & 0.014 \\
\hline & $(0.008)$ & $(0.007)$ & $(0.007)$ & $(0.018)$ & $(0.012)$ & $(0.012)$ \\
\hline \multirow[t]{2}{*}{ Hispanic Driver } & 0.002 & 0.004 & 0.004 & 0.009 & -0.005 & -0.005 \\
\hline & $(0.011)$ & $(0.010)$ & $(0.010)$ & $(0.022)$ & $(0.013)$ & $(0.010)$ \\
\hline \multirow[t]{2}{*}{ Black Officer } & -0.004 & -0.001 & -0.003 & -0.006 & $-0.014^{*}$ & -0.008 \\
\hline & $(0.009)$ & $(0.008)$ & $(0.006)$ & $(0.012)$ & $(0.008)$ & $(0.007)$ \\
\hline \multirow[t]{2}{*}{ Hispanic Officer } & $-0.026 * * *$ & $-0.020 * * *$ & $-0.018^{* * *}$ & -0.004 & -0.005 & -0.003 \\
\hline & $(0.006)$ & $(0.005)$ & $(0.004)$ & $(0.022)$ & $(0.017)$ & $(0.014)$ \\
\hline \multirow[t]{2}{*}{ Mismatch } & 0.008 & 0.010 & 0.008 & $0.026^{*}$ & $0.032 * *$ & $0.024 * *$ \\
\hline & $(0.007)$ & $(0.006)$ & $(0.005)$ & $(0.015)$ & $(0.013)$ & $(0.010)$ \\
\hline \multirow[t]{2}{*}{ Stop at Night } & & $0.025^{* *}$ & $0.022 * *$ & & 0.002 & 0.000 \\
\hline & & $(0.011)$ & $(0.009)$ & & $(0.009)$ & $(0.007)$ \\
\hline \multirow[t]{2}{*}{ Young Driver $($ Age $<26)$} & & $-0.011^{* *} *$ & $-0.009^{*}$ & & $0.024 *$ & $0.021^{*}$ \\
\hline & & $(0.005)$ & $(0.005)$ & & $(0.013)$ & $(0.011)$ \\
\hline \multirow[t]{2}{*}{ Male Driver } & & -0.000 & 0.000 & & 0.009 & 0.008 \\
\hline & & $(0.006)$ & $(0.005)$ & & $(0.008)$ & $(0.006)$ \\
\hline \multirow[t]{2}{*}{ In-State Driver } & & $0.015^{* * *}$ & $0.013^{* * *}$ & & -0.004 & -0.003 \\
\hline & & $(0.005)$ & $(0.004)$ & & $(0.015)$ & $(0.013)$ \\
\hline \multirow[t]{2}{*}{ In-Town Driver } & & $-0.012 * *$ & $-0.011^{*}$ & & 0.013 & $0.013^{*}$ \\
\hline & & $(0.006)$ & $(0.006)$ & & $(0.008)$ & $(0.007)$ \\
\hline \multirow[t]{2}{*}{ Accident } & & 0.005 & 0.004 & & 0.003 & 0.004 \\
\hline & & $(0.009)$ & $(0.007)$ & & $(0.016)$ & $(0.015)$ \\
\hline Neighborhood Controls & NO & NO & YES & NO & NO & YES \\
\hline Observations & 34073 & 33232 & 33232 & 38830 & 37382 & 37073 \\
\hline
\end{tabular}

Robust standard errors in parentheses

$*$ significant at $10 \%$;* significant at $5 \%$; *** significant at $1 \%$ 
Table 14: Racial Composition of Police Districts

\begin{tabular}{|c|c|c|c|c|c|c|c|c|}
\hline & \multicolumn{4}{|c|}{ Census Benchmark } & \multicolumn{4}{|c|}{ Citation-Level Data } \\
\hline & \multicolumn{4}{|c|}{ Population 18 and Older } & \multicolumn{4}{|c|}{ Racial Breakdown of Officers by District } \\
\hline District & White & Black & Hispanic & Asian & White & Black & Hispanic & Asian \\
\hline A-1 & $76.7 \%$ & $3.3 \%$ & $3.2 \%$ & $15.1 \%$ & $62.8 \%$ & $24.8 \%$ & $8.0 \%$ & $4.4 \%$ \\
\hline A-7 & $53.0 \%$ & $2.4 \%$ & $36.6 \%$ & $3.7 \%$ & $72.1 \%$ & $16.4 \%$ & $9.8 \%$ & $1.6 \%$ \\
\hline B-2 & $22.1 \%$ & $47.8 \%$ & $17.0 \%$ & $4.7 \%$ & $51.7 \%$ & $35.7 \%$ & $10.9 \%$ & $1.7 \%$ \\
\hline B-3 & $3.8 \%$ & $78.9 \%$ & $10.8 \%$ & $1.1 \%$ & $55.2 \%$ & $37.3 \%$ & $6.6 \%$ & $0.9 \%$ \\
\hline C-6 & $87.5 \%$ & $1.8 \%$ & $5.2 \%$ & $4.0 \%$ & $76.5 \%$ & $14.8 \%$ & $7.4 \%$ & $1.3 \%$ \\
\hline C-11 & $41.4 \%$ & $28.7 \%$ & $9.0 \%$ & $12.5 \%$ & $70.4 \%$ & $17.3 \%$ & $8.7 \%$ & $3.6 \%$ \\
\hline D-4 & $66.7 \%$ & $9.9 \%$ & $8.8 \%$ & $11.5 \%$ & $69.8 \%$ & $21.2 \%$ & $7.3 \%$ & $1.7 \%$ \\
\hline D-14 & $71.3 \%$ & $3.9 \%$ & $8.0 \%$ & $13.1 \%$ & $71.1 \%$ & $16.3 \%$ & $9.6 \%$ & $3.0 \%$ \\
\hline E-5 & $80.7 \%$ & $6.2 \%$ & $7.8 \%$ & $3.0 \%$ & $71.1 \%$ & $22.2 \%$ & $5.9 \%$ & $0.7 \%$ \\
\hline E-13 & $54.3 \%$ & $15.2 \%$ & $25.0 \%$ & $2.3 \%$ & $60.5 \%$ & $21.6 \%$ & $17.2 \%$ & $0.8 \%$ \\
\hline E-18 & $47.9 \%$ & $33.7 \%$ & $11.9 \%$ & $3.0 \%$ & $59.1 \%$ & $30.7 \%$ & $10.2 \%$ & $0.0 \%$ \\
\hline
\end{tabular}

Source: The Census numbers are taken from the "Massachusetts Racial and Gender Profiling Project:

Preliminary Tabulations," prepared by Northeastern University, Institute on Race and Justice. The citationlevel numbers were derived from our data.

Table 15: Probability of Search, Drivers Stopped in Their Own Neighborhood

\begin{tabular}{|c|c|c|c|}
\hline & (1) & (2) & (3) \\
\hline \multirow[t]{2}{*}{ Black Driver } & 0.010 & 0.002 & 0.005 \\
\hline & $(0.012)$ & $(0.010)$ & $(0.009)$ \\
\hline \multirow[t]{2}{*}{ Hispanic Driver } & -0.003 & -0.009 & -0.010 \\
\hline & $(0.015)$ & $(0.011)$ & $(0.008)$ \\
\hline \multirow[t]{2}{*}{ Black Officer } & -0.002 & -0.009 & -0.006 \\
\hline & $(0.010)$ & $(0.008)$ & $(0.007)$ \\
\hline \multirow[t]{2}{*}{ Hispanic Officer } & $-0.029 * * *$ & $-0.027 * * *$ & $-0.023 * * *$ \\
\hline & $(0.006)$ & $(0.006)$ & $(0.004)$ \\
\hline \multirow[t]{2}{*}{ Mismatch } & $0.025^{* *}$ & $0.029 * * *$ & $0.024 * * *$ \\
\hline & $(0.010)$ & $(0.009)$ & $(0.007)$ \\
\hline \multirow[t]{2}{*}{ Stop at Night } & & 0.003 & 0.004 \\
\hline & & $(0.009)$ & $(0.008)$ \\
\hline \multirow[t]{2}{*}{ Young Driver $($ Age $<26)$} & & 0.015 & 0.013 \\
\hline & & $(0.012)$ & $(0.010)$ \\
\hline \multirow[t]{2}{*}{ Male Driver } & & -0.001 & -0.001 \\
\hline & & $(0.009)$ & $(0.007)$ \\
\hline \multirow[t]{2}{*}{ Accident } & & -0.004 & -0.004 \\
\hline & & $(0.012)$ & $(0.010)$ \\
\hline Neighborhood Controls & NO & NO & YES \\
\hline Observations & 37047 & 36075 & 36075 \\
\hline
\end{tabular}


Table 16: Probability of Search, Drivers Stopped in Their Own Neighborhood Blacks and Whites Only

\begin{tabular}{lccc}
\hline & $(1)$ & $(2)$ & $(3)$ \\
\hline Black Driver & 0.011 & 0.002 & 0.001 \\
& $(0.012)$ & $(0.010)$ & $(0.010)$ \\
Black Officer & 0.003 & -0.006 & -0.006 \\
& $(0.013)$ & $(0.010)$ & $(0.009)$ \\
Mismatch & $0.032^{* *}$ & $0.036^{* * *}$ & $0.031^{* * *}$ \\
& $(0.013)$ & $(0.012)$ & $(0.009)$ \\
Stop at Night & & 0.007 & 0.007 \\
& & $(0.012)$ & $(0.010)$ \\
Young Driver (Age<26) & & 0.018 & 0.018 \\
& & $(0.014)$ & $(0.012)$ \\
Male Driver & & -0.007 & -0.005 \\
& & $(0.011)$ & $(0.009)$ \\
Accident & & -0.004 & -0.003 \\
& & $(0.016)$ & $(0.013)$ \\
Neighborhood Controls & $\mathrm{NO}$ & YES \\
Observations & $\mathrm{NO}$ & 26803 & 26803 \\
\hline Robust stan & 27524 & & \\
\hline
\end{tabular}

Robust standard errors in parentheses

* significant at $10 \%$; ** significant at $5 \%$; *** significant at $1 \%$

Table 17: Probability of Search, Diverse vs. Homogeneous Neighborhoods

\begin{tabular}{|c|c|c|c|c|c|c|}
\hline & \multicolumn{3}{|c|}{ Diverse Neighborhoods } & \multicolumn{3}{|c|}{ Homogeneous Neighborhoods } \\
\hline & (1) & (2) & (3) & (4) & (5) & (6) \\
\hline \multirow[t]{2}{*}{ Black Driver } & $-0.029 *$ & $-0.032 * *$ & $-0.027 *$ & 0.014 & 0.017 & 0.015 \\
\hline & $(0.016)$ & $(0.014)$ & $(0.014)$ & $(0.011)$ & $(0.011)$ & $(0.010)$ \\
\hline \multirow[t]{2}{*}{ Hispanic Driver } & -0.001 & -0.004 & -0.003 & -0.002 & 0.002 & 0.003 \\
\hline & $(0.016)$ & $(0.014)$ & $(0.013)$ & $(0.014)$ & $(0.015)$ & $(0.014)$ \\
\hline \multirow[t]{2}{*}{ Black Officer } & $-0.030 * * *$ & $-0.025^{* * * *}$ & $-0.022 * *$ & 0.006 & 0.008 & 0.009 \\
\hline & $(0.011)$ & $(0.009)$ & $(0.009)$ & $(0.010)$ & $(0.010)$ & $(0.009)$ \\
\hline \multirow[t]{2}{*}{ Hispanic Officer } & -0.014 & -0.016 & -0.012 & $-0.022 * * *$ & $-0.018 * * *$ & $-0.016^{* * *}$ \\
\hline & $(0.015)$ & $(0.012)$ & $(0.013)$ & $(0.006)$ & $(0.006)$ & $(0.005)$ \\
\hline \multirow[t]{2}{*}{ Mismatch } & $0.028^{*}$ & $0.027 *$ & $0.023^{*}$ & $0.016^{*}$ & $0.017 * *$ & $0.015^{* *}$ \\
\hline & $(0.015)$ & $(0.015)$ & $(0.012)$ & $(0.009)$ & $(0.009)$ & $(0.007)$ \\
\hline \multirow[t]{2}{*}{ Stop at Night } & & 0.021 & 0.021 & & 0.006 & 0.004 \\
\hline & & $(0.016)$ & $(0.015)$ & & $(0.009)$ & $(0.008)$ \\
\hline \multirow[t]{2}{*}{ Young Driver $(\mathrm{Age}<26)$} & & 0.003 & 0.002 & & -0.004 & -0.003 \\
\hline & & $(0.013)$ & $(0.012)$ & & $(0.008)$ & $(0.007)$ \\
\hline \multirow[t]{2}{*}{ Male Driver } & & $0.020^{* *}$ & $0.019^{* *}$ & & -0.010 & -0.010 \\
\hline & & $(0.010)$ & $(0.009)$ & & $(0.008)$ & $(0.008)$ \\
\hline \multirow[t]{2}{*}{ In-State Driver } & & 0.009 & 0.005 & & 0.010 & $0.010^{*}$ \\
\hline & & $(0.017)$ & $(0.019)$ & & $(0.007)$ & $(0.006)$ \\
\hline \multirow[t]{2}{*}{ In-Town Driver } & & 0.005 & 0.007 & & -0.002 & 0.000 \\
\hline & & $(0.010)$ & $(0.010)$ & & $(0.007)$ & $(0.007)$ \\
\hline \multirow[t]{2}{*}{ Accident } & & -0.008 & -0.010 & & 0.022 & 0.023 \\
\hline & & $(0.012)$ & $(0.010)$ & & $(0.027)$ & $(0.027)$ \\
\hline Neighborhood Controls & NO & NO & YES & NO & NO & YES \\
\hline Observations & 19758 & 19229 & 19229 & 38655 & 37234 & 37234 \\
\hline
\end{tabular}


Table 18: Probability of Search, Diverse vs. Homogeneous Neighborhoods Blacks and Whites Only

\begin{tabular}{lcccccc}
\hline & \multicolumn{3}{c}{ Diverse Neighborhoods } & \multicolumn{3}{c}{ Homogeneous Neighborhoods } \\
\hline & $(1)$ & $(2)$ & $(3)$ & $(4)$ & $(5)$ & $(6)$ \\
\hline Black Driver & -0.014 & -0.016 & -0.018 & 0.013 & 0.012 & 0.012 \\
& $(0.014)$ & $(0.012)$ & $(0.013)$ & $(0.012)$ & $(0.011)$ & $(0.010)$ \\
Black Officer & $-0.023^{* *}$ & $-0.018^{*}$ & $-0.019^{* *}$ & -0.002 & 0.000 & 0.001 \\
& $(0.012)$ & $(0.010)$ & $(0.010)$ & $(0.011)$ & $(0.009)$ & $(0.009)$ \\
Mismatch & 0.012 & 0.010 & 0.009 & $0.021^{*}$ & $0.022^{*}$ & $0.020^{* *}$ \\
& $(0.013)$ & $(0.012)$ & $(0.011)$ & $(0.013)$ & $(0.011)$ & $(0.010)$ \\
Stop at Night & & 0.029 & 0.027 & & -0.000 & -0.001 \\
& & $(0.021)$ & $(0.019)$ & & $(0.009)$ & $(0.008)$ \\
Young Driver (Age<26) & & -0.005 & -0.005 & & -0.002 & -0.002 \\
& & $(0.013)$ & $(0.013)$ & & $(0.009)$ & $(0.008)$ \\
Male Driver & & 0.014 & 0.012 & & -0.013 & -0.014 \\
& & $(0.011)$ & $(0.009)$ & & $(0.010)$ & $(0.009)$ \\
In-State Driver & & 0.005 & 0.006 & & 0.007 & 0.008 \\
& & $(0.020)$ & $(0.020)$ & & $(0.008)$ & $(0.007)$ \\
In-Town Driver & & 0.003 & 0.003 & & 0.005 & 0.007 \\
& & $(0.011)$ & $(0.012)$ & & $(0.008)$ & $(0.008)$ \\
Accident & & -0.000 & -0.002 & & 0.021 & 0.022 \\
Neighborhood Controls & & $(0.014)$ & $(0.013)$ & & $(0.029)$ & $(0.028)$ \\
Observations & & NO & YES & NO & NO & YES \\
Robust so & & 14506 & 30903 & 29776 & 29776 \\
\hline
\end{tabular}

Robust standard errors in parentheses

$*$ significant at $10 \%$; ** significant at $5 \%$; *** significant at $1 \%$

The neighborhoods categorized as diverse are East Boston (including Charlestown), Roxbury/Mission Hill, Jamaica Plain and

Hyde Park. The neighborhoods characterized as homogeneous are Boston Central, South Boston, Allston/Brighton and West Roxbury/Roslindale. 